\title{
Wearable Wireless Body Area Nodes for Remote Physiological Signal Monitoring System
}

\author{
M. G. Srinivasa ${ }^{1}\left(\mathbb{C}\right.$, P. S. Pandian ${ }^{2 *}$ \\ ${ }^{1}$ Department of Electronics \& Communication Engineering, Thandavapura, Nanjangud Taluk, Mysore, India; \\ ${ }^{2}$ Defence Research \& Development Organization (DRDO), LRDE Campus, C V Raman Nagar, Bangalore, India
}

Correspondence to: P. S. Pandian, pspandian@yahoo.com

Keywords: WPMS, WBAN, Textile Electrode, Sensor Node, Physiological Signals, ZigBee

Received: January 18, 2019 Accepted: February 25, $2019 \quad$ Published: February 28, 2019

Copyright $\odot 2019$ by authors and Scientific Research Publishing Inc.

This work is licensed under the Creative Commons Attribution-NonCommercial International License (CC BY-NC 4.0).

http://creativecommons.org/licenses/by-nc/4.0/

(c) (1) (9) Open Access

\section{ABSTRACT}

Wearable remote health monitoring systems have gained significant prominence in the recent years due to their growth in technological advances. One form of the Wearable Physiological Monitoring System (WPMS) is the Wearable Body Area Networks (WBAN) used to monitor the health status of the wearer for long durations. The paper discusses a prototype WBAN based wearable physiological monitoring system to monitor physiological parameters such as Electrocardiogram (ECG) and Electroencephalogram (EEG) acquired using a textile electrode, Photoplethysmogram (PPG), Galvanic Skin Response (GSR), Blood Pressure derived from analysis of Pulse Transmit Time (PTT) and body temperature. The WBAN consists of three sensor nodes that are placed strategically to acquire the physiological signals and the sensor nodes communicate to a chest/wrist worn sink node also known as wearable data acquisition hardware. The sink node receives physiological data from the sensor nodes and is transmitted to a remote monitoring station. The remote monitoring station receives the raw data and it is processed to remove noises, such as power line interference, baseline wander and tremor in the signals and the information is extracted and displayed. The WBANs are designed using the ZigBee wireless communication modules to transmit and receive the data. At the remote monitoring station the physiological parameters such as heart rate, pulse rate, systolic, diastolic blood pressure, GSR and body temperature are continuously monitored from the wearer. The data acquired from the wearable monitoring system is statically validated using a qualified medical device on 34 subjects.

\section{INTRODUCTION}

This Ischemic heart disease and stroke are considered as the major cause of death in the global popu- 
lation. The reasons for occurrence of these diseases are stress, change in life style, bad food habits, smoking, alcohol consumption, lack of exercise, etc. Proper management of health is vital for maintaining a healthy lifestyle, which requires visit to hospital and a regular health checkup, which was lacking. There is a need to monitor the health status of the individuals non-invasively and at early stage of the disease. Non-invasive devices are commonly available in the market for measurement of various physiological parameters for use in hospitals, clinics and at home. But there is a need for monitoring the health status of the individuals while they perform their routine activities, which is possible by use of wearable devices known as Wearable Physiological Monitoring System (WPMS).

WPMS integrates smart sensors into wearable shirt or a smart wearable device such as a watch to continuously acquire and monitor the health status of the wearer. There has been a tremendous growth in the WPMS in the recent past due to the advancements in smart sensors, microelectronics, digital signal processing techniques and miniaturized wireless communication technologies. The wearable technologies are beneficial in healthcare for early diagnosis and detection of problems, less invasive treatment options, reduction in hospital stay and reduction in rehabilitation time.

The conventional medical devices that are used for health monitoring are not suitable for wearable monitoring due to the following reasons: $[1,2]$

- The existing systems make use of gel electrodes to acquire bio potential signals from the body surface. But these gel electrodes cannot be used for long duration because the gel present in these electrodes gets dried up over a period of time. This increases the skin contact resistance and degrades the quality of the bio potential signals acquired.

- The physiological signals acquired from the gel electrodes are prone to noises such as baseline wander and motion artifacts. These noises arise due to the respiration and physical movement of the subject. Hence the ionic exchange from the skin surface to the electrode gets disturbed.

- Conventional systems are bulky not portable and cannot be used for long duration monitoring.

- The existing systems use wired data acquisition hardware for acquiring bio potential signals. As such the sensors from the body surface are routed with bunch of wires and these wires cause discomfort to the wearer.

- Conventional systems are meant for short duration monitoring and measurements.

- The conventional systems require trained personnel to operate the equipment.

- The conventional systems are too costly and cannot be exploited for wearable health monitoring systems.

Due to the above drawbacks there is a need to develop customized wearable physiological monitoring systems based on the intended use or applications.

There has been tremendous growth in the materials, sensors, microelectronics, wireless communications, high-speed processor \& signal processing technologies. The technological advancements have seen an impact in the health care industry. One such development is the wearable physiological monitoring system. In these systems the sensors and data acquisition systems are integrated into the fabric of the wearer that enables monitoring of the physiological signals in continuous time without need for the intervention of the wearer. The wearable monitoring systems are available in various form factors and can be integrated in shirt, wrist watch, anklets, shoes, socks, chest worn belt, hats, etc. The wearable systems for physiological monitoring are being exploited in a number of health care applications, as follows.

- Monitoring the health conditions of elderly persons at home, individuals with chronic health conditions for timely intervention by doctors.

- Fitness monitoring of individuals using wearable devices to check their day-to-day health status.

- Detection of fall, onset of epileptic seizers, heart attacks, strokes in persons. In these emergency conditions, an alarm is sent to the family members and healthcare providers.

- To know the efficiency and progress of treatments given and monitor physiological changes from chronic conditions.

- Health monitoring of subjects during their routine activity for early detection of symptoms sometimes the health status checkup can be extended for long durations to study their trends, like BP 
monitoring, Heart rate monitoring etc.

- The wearable systems, can be used to monitor the health conditions of some important personnel like soldiers in the battlefield fighting the enemy, fire fighters, miners, deep sea divers and astronauts in space. These persons always risk their lives to protect and complete the assigned task. Hence monitoring their health conditions becomes vital.

The wearable systems for monitoring the physiological signals developed so far targets a number of applications such as home healthcare monitoring [3], physiological status monitoring of soldier's health conditions in a battle field $[4,5]$, monitoring the health status of astronauts in space [6], coal mine workers [7-9], fire fighters fighting fire [10-12], Sudden Infant Death Syndrome (SIDS) [13]. A wearable belt to monitor body temperature, heart and breathing rates and body position of babies has connectivity using ZigBee to monitor SIDS in infants [14]. A wearable system named Health Gear to monitor the users blood oxygen level and pulse while sleeping and algorithms for automatically detecting sleep apnea events and having connectivity to a mobile phone using Bluetooth and the system performance evaluated on 20 volunteers [15]. Sannino et al. have proposed a wearable system that monitors ECG using a mobile phone connectivity and by studying the Heart Rate Variability (HRV) automatically detect sleep apnea [16].

A wearable health monitoring system named WEALTHY integrates sensors, electrodes and the connectivity in fabric form and use advanced signal processing techniques to process. The data is transmitted wireless to a remote monitoring station [17]. A wearable physiological monitoring system named 'Smart Vest' is developed to monitor the ECG acquired from dry electrodes made of Silver filled conducting Silicon rubber electrodes, blood pressure derived from Pulse Transit Time (PTT), body temperature and Galvanic Skin Response (GSR) remotely monitored using wireless communication along with the GPS location of the wearer [18]. An eyeglass based wearable device to monitor Photoplethysmogram (PPG) and ECG is developed to monitor the heart rate and blood pressure derived from PTT [19]. A wrist worn wearable device named "AMON" to monitor and alert high risk cardiac/respiratory patients using cellular communication is developed and validated on 33 subjects [20]. A low cost ZigBee based smart wearable physiological monitoring system to monitor temperature, heart rate and fall detection is developed that can be adapted to monitor athletes, infants and patients recovering from illness at home [21]. A wearable multi-parameter physiological monitoring system termed as LifeGaurd for space and terrestrial applications monitors ECG, respiration rate, heart rate, oxygen saturation in blood, body temperature, blood pressure and three axes acceleration with wireless transmission capability [22]. Vivometrics developed a wearable physiological monitoring known as 'Life Shirt' to monitor various cardio respiratory parameters using conventional sensors [23]. A wearable health monitoring system code named BIOTEX was developed using textile sensors to measure physiological parameters and the chemical composition of the body fluids such as sodium, conductivity, $\mathrm{pH}$ and additionally sweat rate, ECG, respiration and blood oxygenation were also developed [24].

A prototype WBAN using ZigBee communication was developed to monitor physiological, kinetic and environmental sensors. The system provides real-time feedback to the user and generates warnings based on the user's state, level of activity and environmental conditions and the data is transferred to medical servers through the internet for storage and archival [25]. A WBAN to monitor body temperature, heart beat rate and oxygen saturation in blood is developed through ZigBee communication and stored in a centralized server [26]. A network of medical sensors to collect physiological data from patients and transmit it to a PDA using ZigBee to medical server using 3G communications is developed [27]. A WBAN to monitor heart rate and body temperature of multiple patients at home is developed to provide cheaper, easier and quick response if patient has any abnormality [28].

The paper discusses a prototype wearable physiological monitoring system based on the concept of Wearable Body Area Network (WBAN), consisting of sensor node and a sink node to monitor physiological parameters such as ECG, body temperature, EEG, PPG, GSR, and heart/pulse rate. Signal processing algorithms are developed to process the raw signals to remove unwanted noises from the physiological signals such as power line interference, baseline wander, motion artifact and then parameters were extracted for interpretation. The validation of the data is also presented. 


\section{MATERIALS AND METHODS}

\subsection{Wearable Body Area Network (WBAN) Architecture}

The proposed wireless wearable physiological monitoring system consists of three sensors nodes placed strategically at specific locations on the human body to acquire the physiological parameters. Figure 1 illustrates the schematic of the WBAN consisting of three sensor nodes.

The sensor node 1 is to acquire ECG in Lead-I configuration from the upper thorax region and the body temperature of the subject. The sensor node 2 is to acquire one channel of bipolar EEG signal from the frontal pole region. The sensor node 3 is to acquire PPG and GSR signals, the PPG signals are picked from the index finger and the GSR is picked from the medial positions of the index finger and middle finger. The sensor nodes acquire the physiological signals and are transmitted to the sink node or the wearable data acquisition hardware using ZigBee wireless communication. At the sink node the data is received and transmitted wireless to the remote monitoring station for further analysis and interpretation.

\subsection{Physiological Parameters \& Sensors}

The important physiological signals monitored are Electrocardiogram (ECG), Electroencephalogram (EEG), body temperature, PPG, GSR, Blood Pressure and Heart Rate. Table 1 illustrates the specifications of the above parameters monitored and the sensors used.

The ECG and EEG signals are acquired using commercially available conductive textile material. Two types of electrodes were fabricated using $\operatorname{MedTex}^{\mathrm{TM}} 130$ and $\operatorname{MedTex}^{\mathrm{TM}} 180$. The textile material Med$\mathrm{Tex} 130^{\mathrm{TM}}$ is plated with high ionic Silver on Nylon elastic knit material on the both the surfaces, whereas

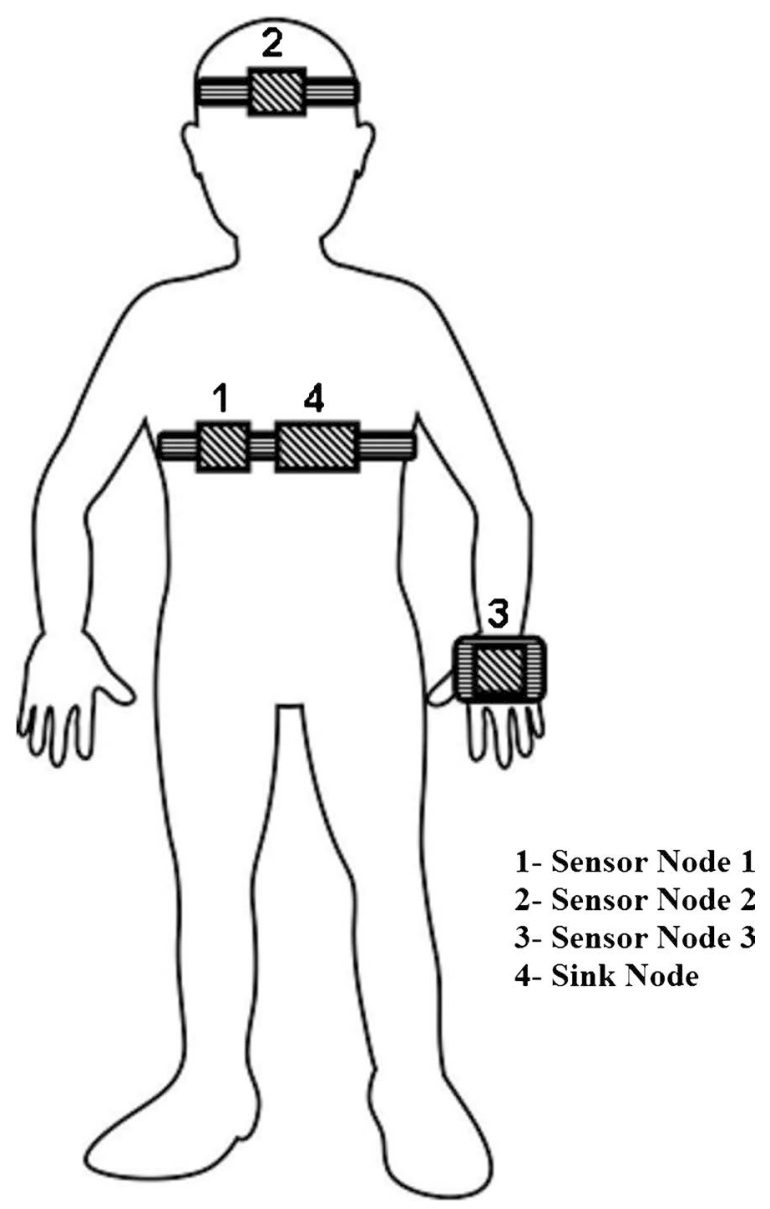

Figure 1. Schematic of Wireless Body Area Network (WBAN) with sensor nodes. 
MedTex $^{\mathrm{TM}} 180$ is coated with Silver on one surface only. The specifications of the textile material used for fabricating the ECG electrode are given in Table 2.

The ECG and EEG electrodes were fabricated with the conductive textiles of length $30 \mathrm{~mm}$ and width $25 \mathrm{~mm}$ and the connector was made at one edge of the electrode using a stainless steel connector. The electrodes were fabricated for the acquisition of ECG Lead-I and EEG signal from the frontal pole region. The GSR electrodes were also fabricated with conductive textile material of length $15 \mathrm{~mm}$ and width 10 $\mathrm{mm}$ and the connectors were made using stainless steel. Figure 2(a) illustrates the schematic of the sensor node integrated into a chest belt with ECG electrodes, temperature sensor and the wearable data acquisition hardware and Figure 2(b) illustrates the schematic of the sensor node, integrated with EEG electrodes to acquire from the frontal pole region.

Table 1. Physiological parameters monitored and their specifications.

\begin{tabular}{cccc}
\hline \multirow{2}{*}{ SL. No } & Parameter & \multicolumn{2}{c}{ Specifications } \\
\cline { 3 - 4 } & & Type $1 \mathrm{MedTex}^{\mathrm{TM}} 130$ & ${\text { Type } 2 ~ \text { MedTex }^{\mathrm{TM}} 180}^{2}$ \\
\hline 1 & Surface Resistance & $<5$ & $<5 \Omega$ \\
2. & Plating & $99.9 \%$ pure Silver & $99.0 \%$ pure Silver \\
3 & Abrasion Resistance & 100,000 Cycles & 100,000 Cycles \\
4. & Total Thickness & $0.45 \mathrm{~mm}$ & $0.554 \mathrm{~mm}$ \\
5. & Weight & $140 \mathrm{~g} / \mathrm{m}^{2}$ & $224 \mathrm{~g} / \mathrm{m}^{2}$ \\
6 & Material & $78 \%$ Nylon $+18 \%$ Elastomer & $78 \%$ Nylon $+22 \%$ Elastomer \\
\hline
\end{tabular}

Table 2. Electrode Specifications.

\begin{tabular}{|c|c|c|c|}
\hline SL. No & Physiological Parameter & $\begin{array}{c}\text { Physiological Signal Specifications \& } \\
\text { Sensor }\end{array}$ & Sensor \\
\hline 1 & $\begin{array}{l}\text { Electrocardiogram } \\
\text { (ECG) }\end{array}$ & $\begin{array}{l}\text { Frequency: } 0.5-100 \mathrm{~Hz} \\
\text { Amplitude } 0.25-1 \mathrm{mV}\end{array}$ & $\begin{array}{l}\text { Textile Electrode } \\
(30 \mathrm{~mm} \times 25 \mathrm{~mm})\end{array}$ \\
\hline 2. & Heart Rate & $\begin{array}{l}40 \text { - } 220 \text { Beats per minute Measured } \\
\text { from ECG Signal }\end{array}$ & Measured from ECG Signal \\
\hline 3. & $\begin{array}{l}\text { Electroencephalogram } \\
\text { (EEG) }\end{array}$ & $\begin{array}{c}\text { Frequency } 0.5-35 \mathrm{~Hz} \\
\text { Amplitude: } 10 \mu \mathrm{V} \text { to } 100 \mu \mathrm{V}\end{array}$ & $\begin{array}{l}\text { Textile Electrode } \\
(15 \mathrm{~mm} \times 10 \mathrm{~mm})\end{array}$ \\
\hline 4. & Body Temperature & $0^{\circ} \mathrm{C}-40^{\circ} \mathrm{C}$ Resolution $\pm 0.01^{\circ} \mathrm{C}$ & Thermistor YSI 409B \\
\hline 5. & $\begin{array}{l}\text { Blood Pressure (Systolic } \\
\text { and Diastolic) }\end{array}$ & $\begin{array}{l}\text { Derived from analysis of Pulse } \\
\text { Transmit Time (PTT) Systolic: } 50-300 \\
\text { mmHg; diastolic: } 40-140 \mathrm{mmHg}\end{array}$ & $\begin{array}{l}\text { PTT measured from PPG } \\
\text { and ECG signals }\end{array}$ \\
\hline 6. & $\begin{array}{l}\text { Galvanic Skin Response } \\
\text { (GSR) }\end{array}$ & Skin Resistance 0 to $100 \mathrm{~K} \Omega$ & $\begin{array}{l}\text { Textile Electrode } \\
(10 \mathrm{~mm} \times 15 \mathrm{~mm})\end{array}$ \\
\hline 7. & $\begin{array}{l}\text { Photoplethysmogram } \\
\text { (PPG) }\end{array}$ & Frequency: $0.5-20 \mathrm{~Hz}$ & $\begin{array}{l}\text { Red Light LED source at } 670 \\
\mathrm{~nm} \text { and } 3 \mathrm{~mW} \text { power }\end{array}$ \\
\hline
\end{tabular}




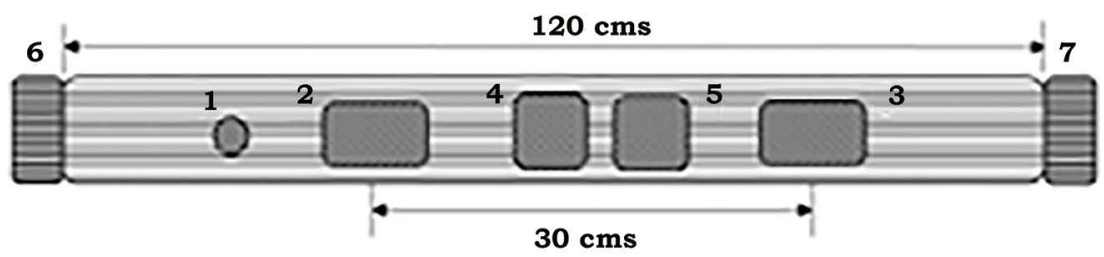

(a)

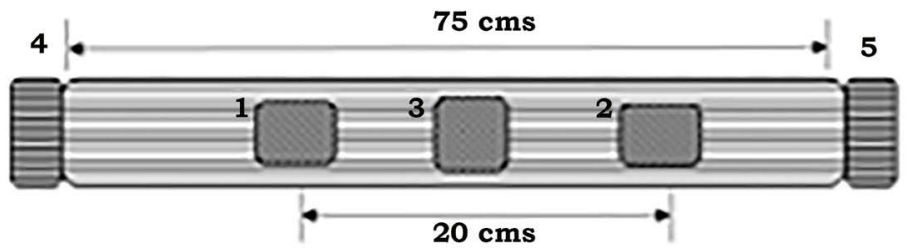

5

(b)
1. Thermistor

$2 \& 3$ - ECG Electrode

4 - Sensor Node 1

5 - Sink Node

$6 \& 7$ - Connectors
1 \& 2 - EEG Electrode

3 - Sensor Node - 2

4 \& 5 - Connectors

Figure 2. Textile Electrode integrated to belt with sensor node to acquire (a) ECG (b) EEG signals.

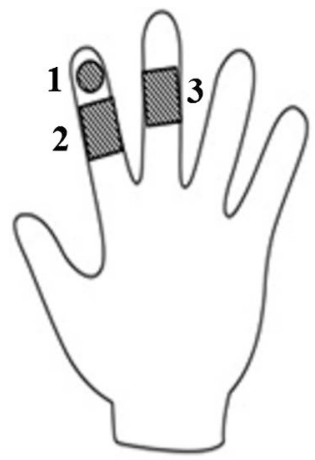

(a)

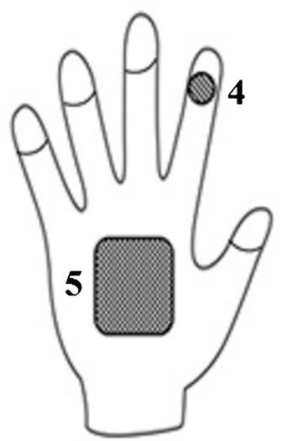

(b)
1- Photodetector

2 \& 3 - GSR Electrode

4 - LED Source

5 - Sensor Node 3

Figure 3. Schematic of gloves with integrated GSR Electrodes, PPG Sensors \& Sensor Node 3 (a) Palm side (b) Back side.

Figure 3 illustrates the schematic of the sensor node, which is worn in the form of a gloves with integrated with textile electrodes for GSR measurement and PPG acquisition with source and photo detector integrated into the gloves.

\subsection{Textile Electrode Characterization}

Electrodes are the key components for recording the bio-potential signals in wearable monitoring systems, their characteristics will decide the quality of bio-potential signals recorded. The electrodes contact impedance of electrode-skin interface for wet $\mathrm{Ag}-\mathrm{AgCl}$, dry $\mathrm{Ag}-\mathrm{AgCl}$, textile electrodes type 1 and type 2 are calculated. The contact impedance measurement setup is shown in Figure 4(a) \& Figure 4(b) that uses four electrodes E1 - E4 of the same types, which are placed on forearm with $50 \mathrm{~mm}$ spacing for the electrodes. An arbitrary waveform generator (Model No BK Precision 4055B) was used to feed a sinusoidal wave with frequency from $\mathrm{DC}$ to $10 \mathrm{KHz}$ and voltage $1 \mathrm{mV}$. The potential across the electrodes are measured using a digital multimeter (Key Sight Technologies Model No. 34470A).

From Figure 4(a), The $\left[R_{A} \| C_{1}\right],\left[R_{B} \| C_{2}\right],\left[R_{C} \| C_{3}\right],\left[R_{D} \| C_{4}\right]$ represents the resistance \& capacitance combination of the Electrodes. $R_{\text {skin }} \& R_{\text {body }}$ representing the skin and the body resistance.

From Figure 4(a), the total impedance is given by,

$$
Z_{\text {Total }}=\left[Z_{\text {Contact }}+Z_{\text {SkinBody }}\right]
$$

where, 


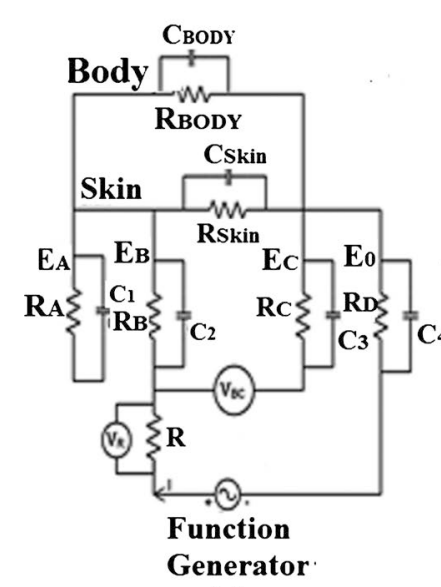

(a)

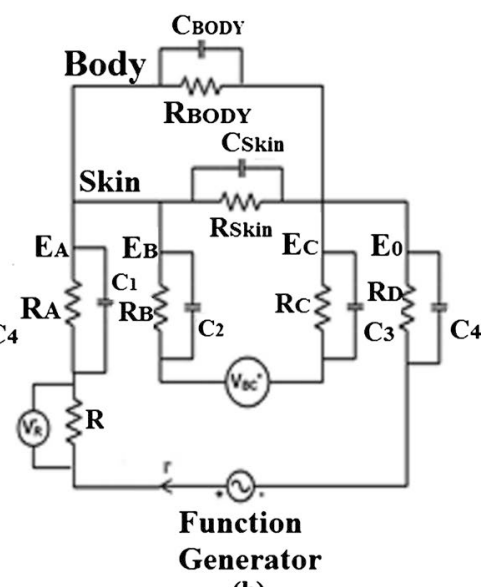

(b)

Figure 4. Experimental setup to measure (a) equivalent impedance of skin and body between the electrodes (b) for measuring the contact impedance.

$$
\begin{gathered}
Z_{\text {Total }}=\frac{R_{B} \times X_{C 2}}{R_{B}+X_{C 2}}+\left[R_{\text {Body }} \| C_{B}\right] \|\left[R_{\text {Skin }} \| C_{\text {Skin }}\right] \\
Z_{\text {Total }}=\frac{V_{B C}}{I}
\end{gathered}
$$

and $I=\frac{V_{R}}{R}$.

From Figure 4(b) the impedance of skin and body between the two electrodes $E_{B}$ and $E_{C}$ is given by,

$$
\begin{gathered}
Z_{\text {SkinBody }}=\left[R_{\text {Body }} \| C_{B}\right] \|\left[R_{\text {Skin }} \| C_{\text {Skin }}\right] \\
Z_{\text {SkinBody }}=\frac{V_{B C}^{\prime}}{I^{\prime}}
\end{gathered}
$$

and $I^{\prime}=\frac{V_{R}^{\prime}}{R}$

The contact impedance is given by,

$$
\begin{gathered}
Z_{\text {Contact }}=Z_{\text {Total }}-Z_{\text {SkinBody }} \\
Z_{\text {Contact }}=\frac{R_{B} \times X_{C 2}}{R_{B}+X_{C 2}}
\end{gathered}
$$

where, $X_{C 2}$ represents the reactance

$$
Z_{\text {Contact }}=\frac{V_{B C}}{I}-\frac{V_{B C}^{\prime}}{I^{\prime}}
$$

The contact impedances for the four types of electrodes considered for wearable monitoring were measured and analyzed.

\subsection{Sensor Nodes and Wearable Data Acquisition Hardware}

The WBAN consists of three sensor nodes, wearable data acquisition hardware and remote monitoring station. The sensor nodes are independent units that have dedicated functioning to acquire the physiological parameters and communicate them wireless to a sink node and from the sink node the data is transmitted to the remote monitoring station. 


\subsubsection{Sensor Node 1}

The Sensor Node 1 is used to acquire ECG signal in the Lead-I configuration and body temperature from the arm pit of the subject. Figure 5 illustrates the block diagram of sensor node 1 . It consists of instrumentation amplifier for signal conditioning the weak ECG signal and the temperature inputs. Further it consists of microcontroller used for digitizing the raw inputs, wireless communication module for transmitting the sensor node 1 data to the remote station along with the power supply circuitry. The instrumentation amplifier is built using the INA128 OP-AMP which has high Slew rate and high CMRR of the order of $130 \mathrm{~dB}$. The first stage of the ECG amplifier has a gain of 10 followed by $2^{\text {nd }}$ order Butterworth Bandpass filter circuit with the frequency range of $0.5-100 \mathrm{~Hz}$. The $2^{\text {nd }}$ stage amplifier has a gain of 100 followed by a notch Filter stage used to remove the $50 \mathrm{~Hz}$ power line frequency. The notch filter makes uses of active Twin-Tee network in the filtering stage. The other circuit consists of temperature signal conditioning circuitry with a gain of 10. The input to this amplifier is from the temperature sensor YSI409B.The conditioned signals are fed to the digital section with suitable buffers. The digital section is based 8-bit ATmega Microcontroller from Arduino. The Analog signals are digitized using a built-in 10-bit ADC. The ZigBee wireless communication module is interfaced to the UART of microcontroller. The sampling rate for the signal acquisition is at 250 samples per second. The acquired data are framed into packets and transmitted wireless to the remote monitoring station. The power supply section consists of a 7.4 V Lithium-Polymer battery at $1.8 \mathrm{AH}$ rating. Regulator LM7805 is used to get $5 \mathrm{~V}$ and power the wearable data acquisition hardware and LD1117 3.3 V regulator is used to power the microcontroller and the wireless communication module.

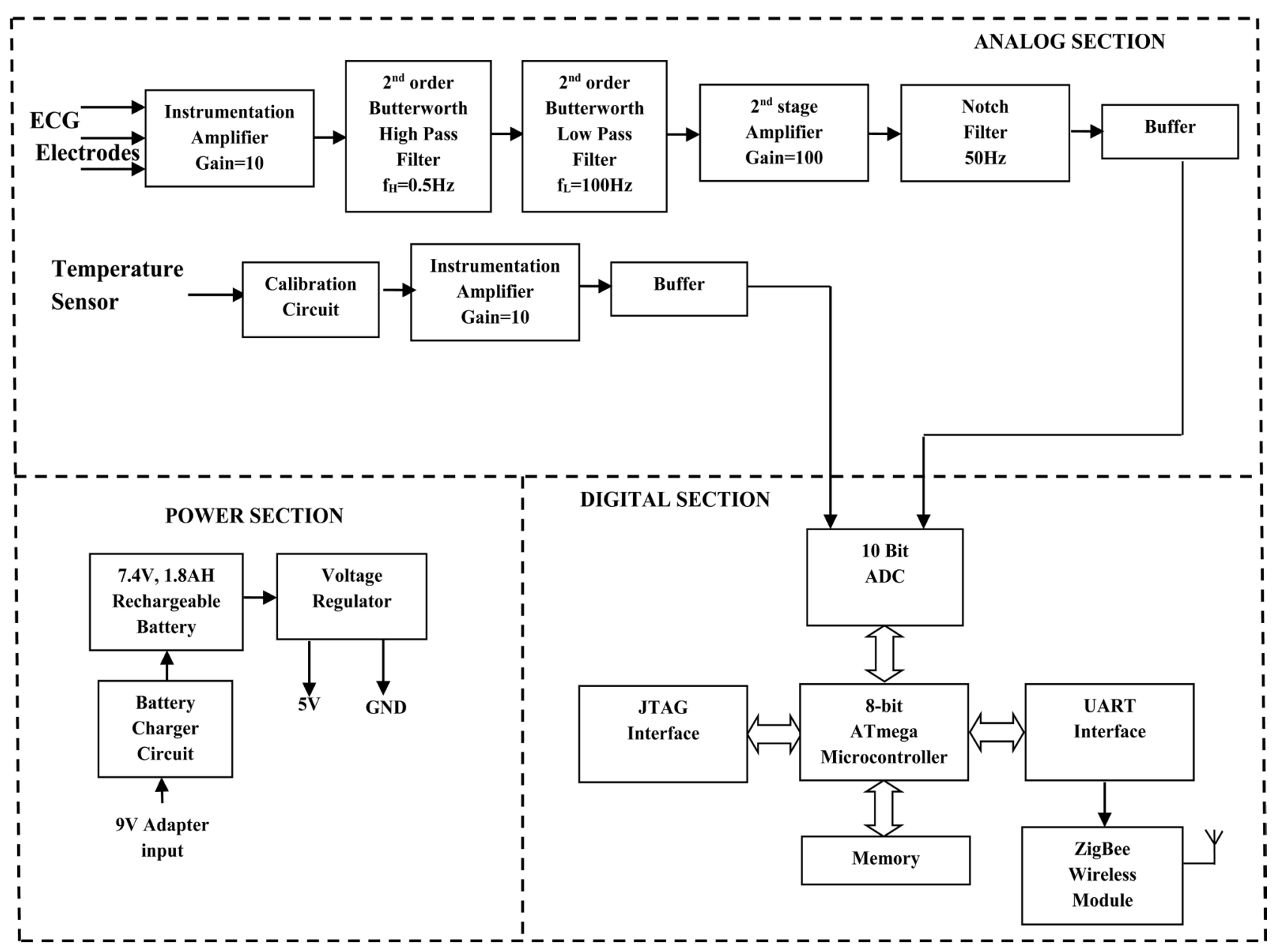

Figure 5. Block Schematic of the Sensor Node 1 to acquire ECG \& body temperature. 


\subsubsection{Sensor Node 2}

The sensor node 2 is used to acquire the EEG Signal. Figure 6 illustrates the block diagram of the sensor node 2.

It consists of signal conditioning circuit for the EEG, digital section and power supply. The overall gain of EEG amplifier is 5000 and the band pass filters used are $2^{\text {nd }}$ order Butterworth filter which has the frequency range $0.5-35 \mathrm{~Hz}$. The digital sections, power and wireless communications sections are similar to that of the sensor node 1 .

\subsubsection{Sensor Node 3}

Sensor node 3 is used to acquire PPG and GSR signals. Figure 7 illustrates the block diagram of the sensor node 3.

It consists of Instrumentation and Conditioning circuit for the PPG and GSR signals. The PPG sensor uses a red light source operating at a wavelength of $670 \mathrm{~nm}$ with $3 \mathrm{mw}$ power. The output of the photodetector is fed to an I-V converter and signals are band limited to $0.5-20 \mathrm{~Hz}$ using a $2^{\text {nd }}$ order Butterworth filter. The signals are further amplified using a amplifier (INA128) with a gain of 20.

\subsubsection{Sink Node}

The Sink node to acquire the data's from the sensor nodes is as shown in Figure 8.

The physiological data acquired from the sensor nodes are received at the sink node. The sink nodes coordinate the data acquisition from the sensor nodes. The data acquired is transmitted to the remote monitoring station using Bluetooth wireless communication module. At the remote monitoring station the data is received, processed and displayed. The sink node architecture is star network and the data is read from the sensor nodes in a round robin fashion at a programmed predetermined intervals.

\subsection{Blood Pressure Measurement from PTT}

The noninvasive blood pressure measurement techniques are indirect methods and are based on

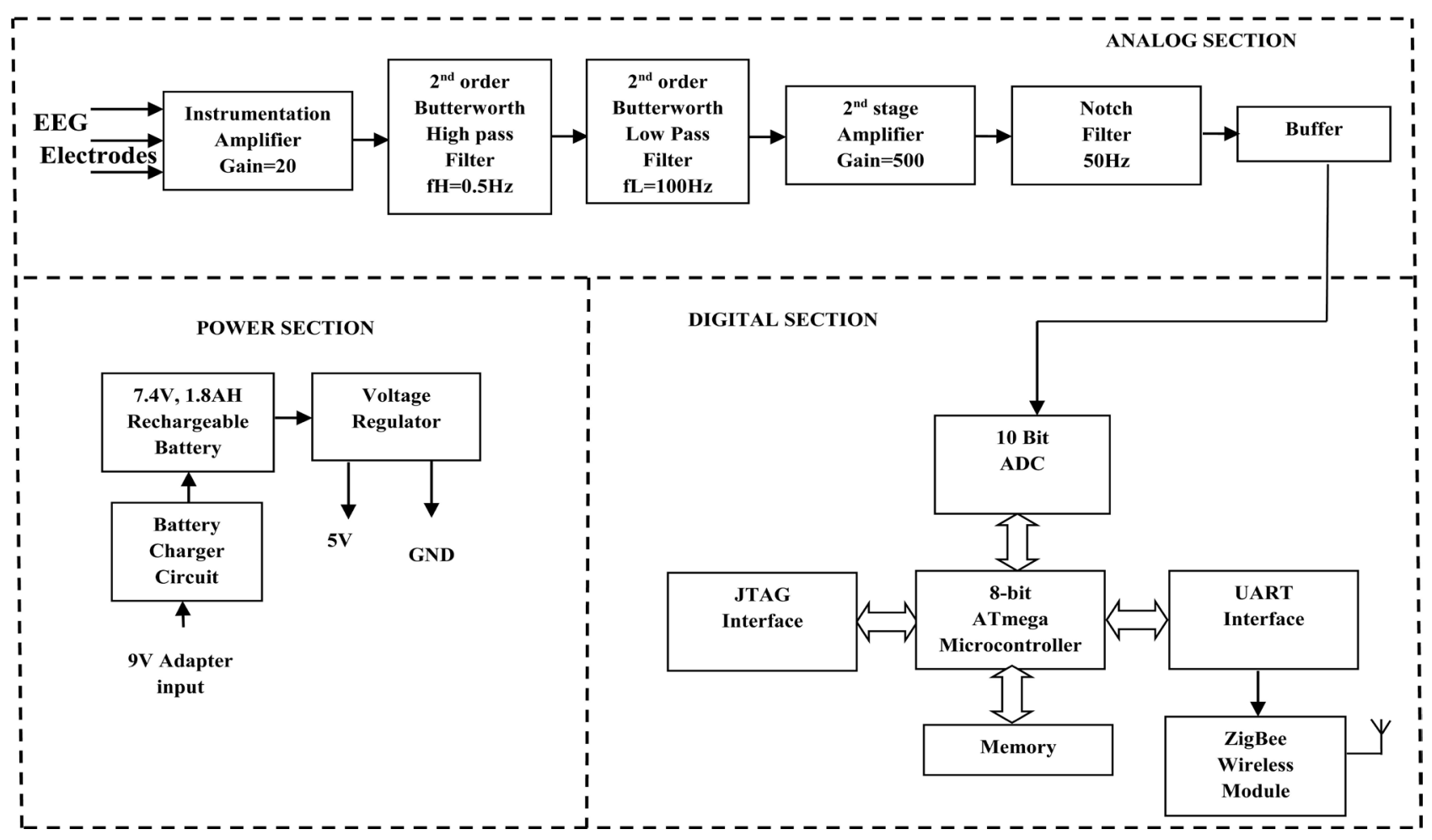

Figure 6. Block Schematic of the Sensor Node 2 to acquire EEG signals. 


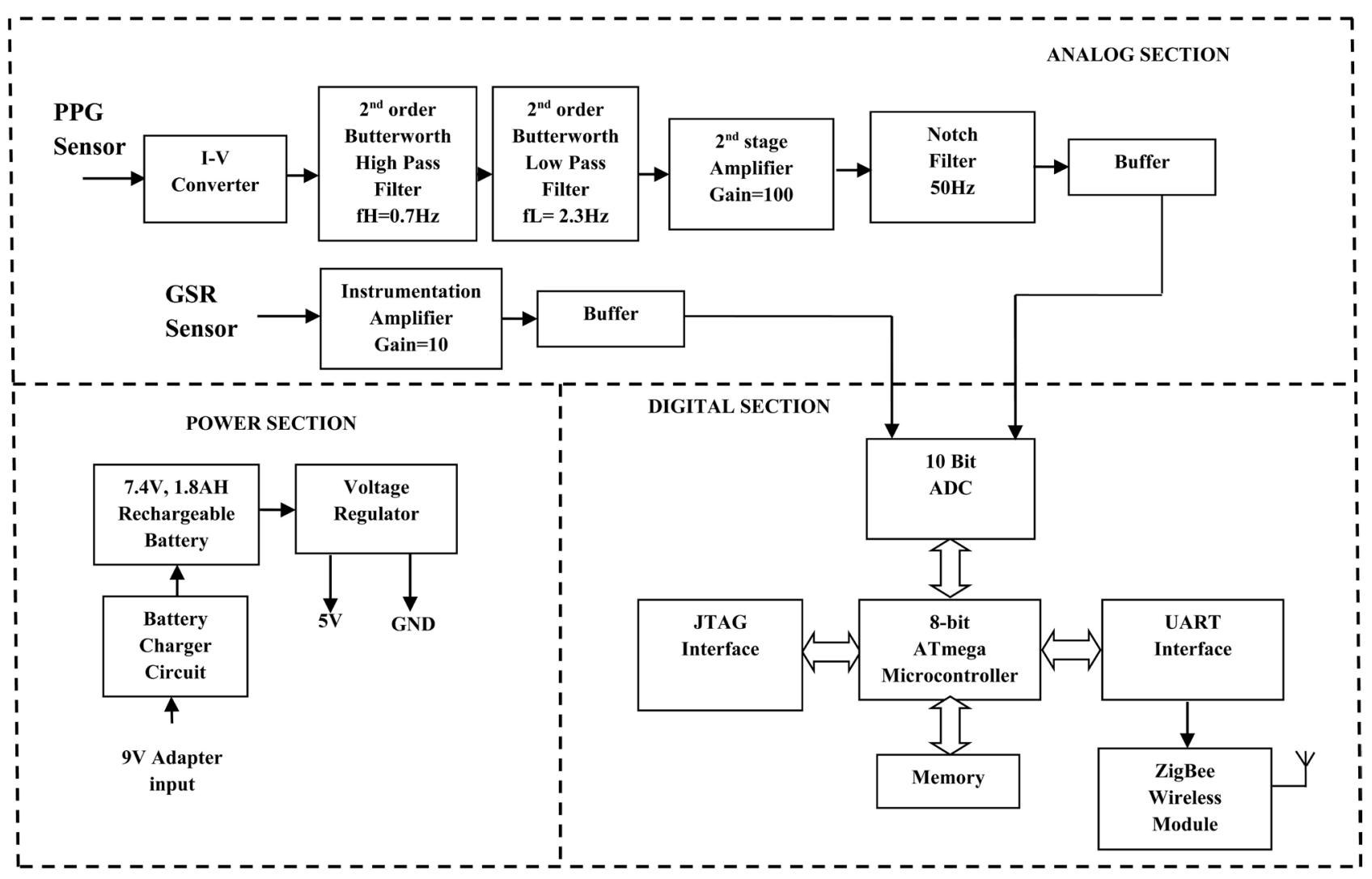

Figure 7. Block Schematic of the Sensor Node 3 to acquire PPG and GSR signals.

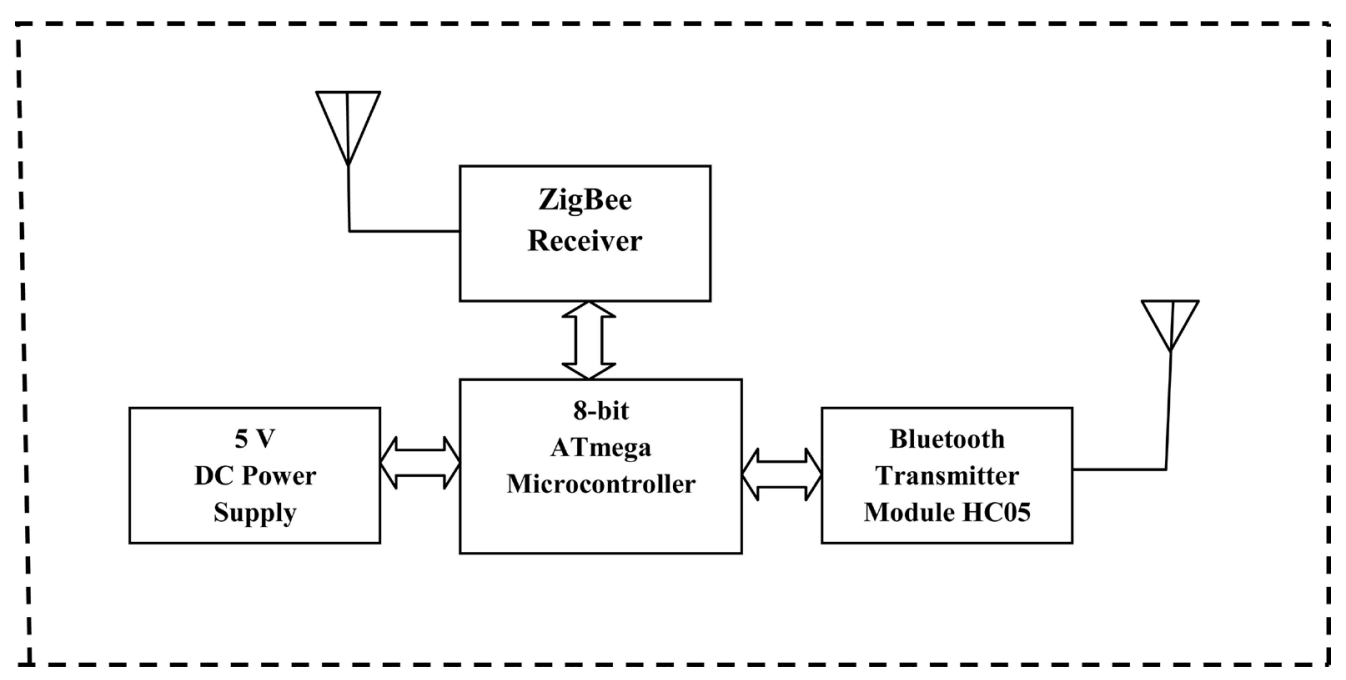

Figure 8. Block Schematic of the Sink Node.

measurement of counter pressure. The conventional cuff-based methods for blood pressure measurements are not viable in wearable physiological monitoring applications. Altenate indirect methods are being used to derive blood pressure, Pulse Transmit Time (PTT) is one of the commonly used physiological parameter to estimate the Systolic (SBP) and Diastolic (DBP) Blood Pressures. The PTT is measured as the interval between the peak of R-wave of ECG and fingertip PPG signal, as illustrated in Figure 9.

The estimation of blood pressure based on the PTT as one factor is not accurate as there are a number of factors contributing for it to be estimated accurately. The earlier methods proposed require a prior 


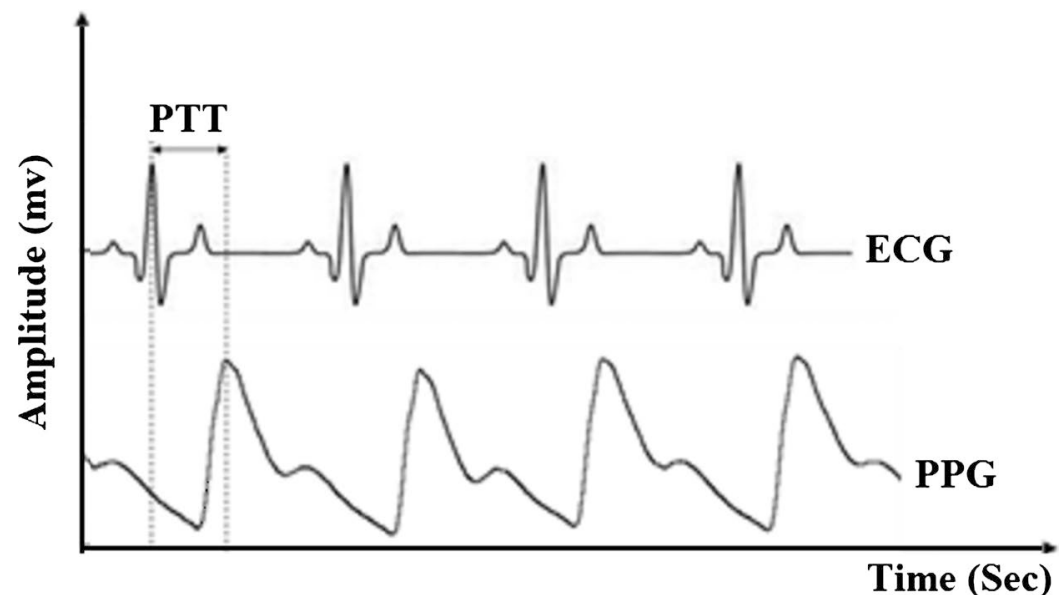

Figure 9. PTT measurement from ECG and PPG signal.

calibration to be carried for every individual before the measurements are being carried, which is time consuming and not feasible for wearable monitoring applications $[29,30]$. The factors other than PTT that influence the correct estimation of blood pressure are heart rate, arterial stiffness, blood viscosity, age, height, weight, external temperature, location where the PPG signal is measured. A PTT based method of $\mathrm{BP}$ estimation considering various factors such as heart rate, age, height, weight is analyzed and by the linear regression model with dynamic pulse transmit time analysis the following SBP and DBP equations are derived. Also the need for calibration before the measurement is not required. The systolic blood pressure (SBP) and diastolic blood pressure (DBP) for a particular pulse related to instantaneous heart rate are given by the following equations.

$$
\begin{aligned}
\mathrm{SBP}= & (0.1989 \times \text { Age })+(0.318 \times \mathrm{HR})+(0.1946 \times \mathrm{WT}) \\
& -(0.2395 \times \mathrm{HT})-(330.5 \times \mathrm{PTT})+146.917 \\
\mathrm{DBP}= & (0.0772 \times \mathrm{Age})+(0.1122 \times \mathrm{HR})+(0.0893 \times \mathrm{Wt}) \\
& -(0.1135 \times \mathrm{HT})-(19.778 \times \mathrm{PTT})+91.595
\end{aligned}
$$

\subsection{Signal Processing}

The ECG signal is corrupted with different types of noises and the common noises are the baseline wander and motion artifacts, which are added due to the breathing and movement of the subjects.. The baseline noise is a low frequency noise added to the ECG signal which can be removed by use of a High Pass Filter (HPF). The motion artifacts are caused due to the relative motion of electrodes with the movement of the subject. These motion artifacts are high frequency noise that can be removed by use of a Low Pass Filters (LPF). These noises are filtered using digital filtering techniques using the Finite Impulse Response (FIR) as they have several advantages [31,32]. The Kaiser window is chosen for the implementation of the FIR filter to remove the presence of large oscillations in both pass band and stop band, Kaiser Window function is chosen. The Kaiser window is defined by

$$
w[n]= \begin{cases}\frac{I_{0}\left[\beta \sqrt{1-\left(\frac{2 n}{N-1}\right)^{2}}\right]}{I_{0}[\beta]} & 0 \leq n \leq N-1 \\ 0 & \text { otherwise }\end{cases}
$$

where, $I_{0}[x]$ is the zero-order modified Bessel function of the first kind and is given as 


$$
I_{0}[x]=1+\sum_{k=1}^{L}\left[\frac{x / 2}{k !}\right]^{2}
$$

and the ripple control parameter $\beta$ is defined by

$$
\left\{\begin{array}{lc}
\beta=0 & A \leq 21 \mathrm{~dB} \\
\beta=0.5842(A-21)^{0.4}+0.07886(A-21) & 21 \mathrm{~dB} \leq A \leq 50 \mathrm{~dB} \\
\beta=0.1101(A-8.7) & A \geq 50 \mathrm{~dB}
\end{array}\right.
$$

The filter coefficients of a digital filter is given by

$$
h[n]=h_{d}[n] * w[n]
$$

where $h_{d}[n]$ is time-domain impulse response of the filter and $w[n]$ is the window function. In the proposed work both LPF and HPF functions are used with Kaiser Window.

Hence, $h_{d}[n]$ for LPF used to remove the tremor in the bio-potential signals is given by

$$
\begin{gathered}
h_{d}[n]=\frac{w_{c} \sin \left(n-\left(\frac{N-1}{2}\right) w_{c}\right)}{\pi\left(n-\left(\frac{N-1}{2}\right) w_{c}\right)} \\
w_{c}=\frac{2 \pi f_{c}}{f_{s}}
\end{gathered}
$$

The $h_{d}[n]$ for HPF used to remove the tremor in the bio-potential signals is given by

$$
h_{d}[n]=\frac{1}{n \pi}\left[\sin (\pi n)-\sin \left(w_{c} n\right)\right]
$$

where $f_{c}$ is the cut off frequency and $f_{s}$ is the sampling frequency.

\subsection{Data Validation}

The wearable physiological monitoring system was tested on 35 healthy subjects male subjects to study the consistency and reliability of the data recordings as compared to that of the standard devices. The study was carried out on 35 healthy male subjects in the age group of $25-87$ years and their prior consent was obtained. Out of the 35 subject, one subject could not complete the task, the validation of the data was carried out with 34 subjects. The validation was carried out for $30 \mathrm{~min}$ on each subject during resting, walking and mild exercise conditions and the physiological parameters were acquired simultaneously from both the devices. The systolic, diastolic blood pressure and heart rate data were analyzed statistically by Bland-Altman method $[33,34]$ and were plotted as the difference in measurements against mean of the two measurements. The bias was calculated from the average of the differences between the two methods and precision was calculated from the standard deviation of the differences between the methods. The bias and precision determined were analyzed to estimate the performance of the device.

\subsection{Heart Rate Variability (HRV)}

The heart rate variability is the physical phenomenon that reveals the beat-to-beat variations in the $\mathrm{R}-\mathrm{R}$ interval. There are many methods used to analyze HRV signals. Most commonly used methods are time domain, frequency domain and nonlinear methods. In frequency domain HRV signals are trans- 
formed to Power spectral density (PSD) by using Discrete Fourier Transform (DFT). Most commonly used HRV spectrum for analysis in frequency domain are very low frequency (VLF: $<0.04 \mathrm{~Hz}$ ), low frequency (LF: $0.04-0.12 \mathrm{~Hz}$ ) and high frequency (HF: $0.12-0.4 \mathrm{~Hz}$ ). HRV is relevant to many cardiovascular and non-cardiovascular diseases such as high BP, diabetic neuropathy, sudden cardiac death, myocardial infarction, etc. In the proposed work the time domain and frequency domain analysis of R-R and hear rate variations over the extended period of time are done and mean HR variations were computed for the subject.

\subsubsection{Time Domain Analysis}

HRV time domain analysis method is being considered for the study due its simplicity compared to other assessment techniques as it is directly calculated from RR interval time series [35]. In the HRV time domain analysis, RR intervals are commonly mentioned as NN (normal-to-normal) intervals. This is due to the fact that only intervals between successive QRS complexes generated by normal sinus depolarization are examined for this study [36]. The time-domain features are commonly computed using mean and the standard deviation of the RR interval series. Following are the time domain parameters computed in this study for stress classification.

- Average Heart Rate

It is the number of heart beats per minute and it is defined as

$$
\text { Heart Rate }(H R)=\frac{\text { Number of RR Intervals }}{\text { Duration in Minute }}
$$

- SDNN

The standard deviation of NN intervals (SDNN) for the given segment of data, is described as the square root of the variance of the NN intervals. Since the variance in the time domain is equal to the total power in the frequency domain, SDNN describes the cyclic components accountable for variability [37]. Mathematically, SDNN is defined as:

$$
\mathrm{SDNN}=\sqrt{\frac{\sum_{i=1}^{n}\left(R R_{i}-R R_{\text {mean }}\right)^{2}}{N-1}}
$$

where

$$
R R_{\text {mean }}=\frac{\sum_{i=1}^{n} R R_{i}}{N}
$$

- SDSD

The standard deviation of the successive differences of the NN intervals describes the short-term variation in RR interval series. It can be described as:

$$
\mathrm{SDSD}=\sqrt{\frac{\sum_{i=1}^{n}\left(\left|R R_{i}-R R_{i+1}\right|-R R_{\text {diff }}\right)^{2}}{N-1}}
$$

where

$$
R R_{\text {diff }}=\frac{\sum_{i=1}^{n}\left|R R_{i}-R R_{i+1}\right|}{N-1}
$$

- RMSSD

Root-mean-square of successive differences of adjacent NN intervals. Similar to SDSD, RMSSD also shows the short-term variability of the RR interval series. It can equivalent to the high frequency variation in the spectral analysis [38]. 
Mathematically RMSSD can defined as $\mathrm{RMSSD}=\sqrt{\frac{\sum_{i=1}^{n}\left(R R_{i+1}-R R_{i}\right)^{2}}{N-1}}$.

- $\quad \mathrm{NN} 50$ and pNN50

NN50 is the number of consecutive RR intervals that differ more than $50 \mathrm{msec}$ and pNN50 is the fraction obtained by dividing NN50 by the total number of RR intervals in the given segment [39] pNN50 is utilized for the estimation of the high-frequency variation in RR interval series. Unlike RMSSD, pNN50 is much less susceptible to the presence of noise and artifact in the recording [40]. Mathematically, it is defined as:

$$
\begin{gathered}
\mathrm{NN} 50=\sum_{i=1}^{n}\left\{\left|R R_{i+1}-R R_{i}\right|>50 \mathrm{~ms}\right\} \\
\mathrm{pNN} 50=\frac{\mathrm{NN} 50}{N} \times 100 \%
\end{gathered}
$$

\subsubsection{Frequency Domain Analysis}

The frequency domain parameters give the accurate and effective feature evaluation of HRV compared to time domain [41]. In this analysis the power spectral density (PSD) of HRV is calculated. The output gives the information about power distribution of spectral components obtained from RR intervals. The high frequency (HF) is characterised by the parasympathetic activity of the autonomous nervous system whereas the low frequency (LF) is a good indicator of both parasympathetic and sympathetic activity. The LF, HF components and also the LF/HF ratio are used to indicate the stress or fatigue level of the subject under test. There is approximate correlation between time and frequency domain evaluation parameters [42]. The spectral features of HRV were calculated from RR interval data by power spectral density (PSD) using periodogram. The RR interval is sampled [43] at a frequency of $8 \mathrm{~Hz}$. The RR interval samples were divided into overlapping segments with $50 \%$ overlap. Figure 10 shows the PSD of the RR interval data over the frequency range of $0-0.4 \mathrm{~Hz}$.

The steps for calculating the power spectral density [44] is a) Applying FFT to RR interval data b) Applying Hanning window function with $50 \%$ overlap c) Plotting the PSD.

\subsubsection{Non Linear Methods}

The nonlinear method of estimating HRV is by using Poincare plot as shown in Figure 11.

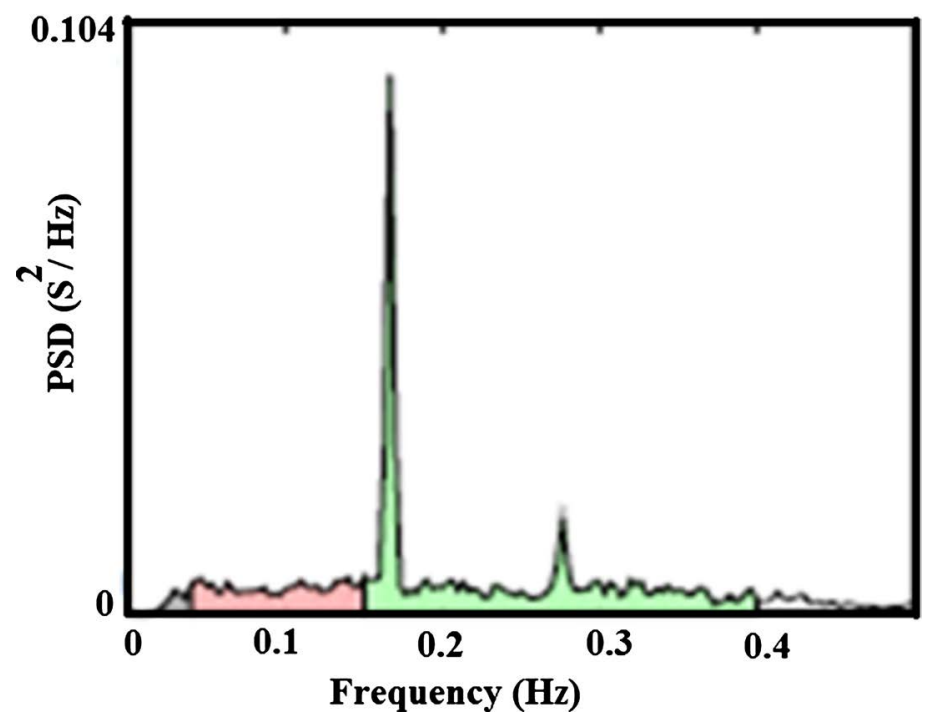

Figure 10. PSD of the RR Interval in the frequency Range $(0-0.4 \mathrm{~Hz})$. 


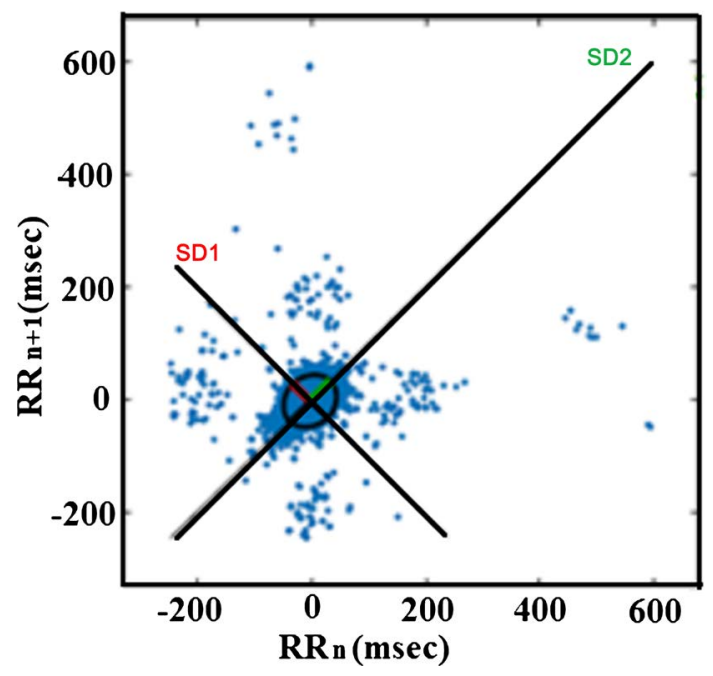

Figure 11. Poincare Plot showing the correlation between Successive RR intervals.

It represents the correlation [45] between successive RR intervals. It also gives information about heart behavior based on beat to beat RR interval repetitions. The Poincare plot is typically described by two descriptors SD1 and SD2 where SD1 represents the standard deviation of the points across the line of identity and SD2 represents the standard deviation of the points along the line of identity.SD1 describes the short term variability and the parasympathetic activity of the autonomous nervous system and SD2 describes the long term variability [46] and the sympathetic activity of the autonomous nervous system. The SD1 and SD2 are calculated using the following equations.

$$
\begin{aligned}
& S D_{1}=\sqrt{\text { Variance }\left(S_{1}\right)} \\
& S D_{2}=\sqrt{\operatorname{Variance}\left(S_{2}\right)}
\end{aligned}
$$

where $S_{1}=\left(R R_{i}-R R_{i+1}\right) / 2 \quad R R_{i}=\left(R R_{1}, R R_{2}, \cdots, R R_{N-1}\right)$

$$
\begin{gathered}
S_{2}=\left(R R_{i}+R R_{i+1}\right) / 2 \\
R R_{i+1}=\left(R R_{2}, R R_{3}, \cdots, R R_{N}\right)
\end{gathered}
$$

\section{RESULTS}

Figure 12 illustrates the contact impedances measured for all the four types of electrodes, from the plot of the frequency versus impedance it is observed that the variations of contact impedance of all the four types of electrodes follow the same tendency as a function of frequency.

The results were found to be in agreement with the published literature [47, 48]. The electrodes were electrically modeled as a resistance and capacitance connected in parallel, where at low frequencies the value of the impedance is by the resistance and with the increasing frequency, the contribution from capacitance is more dominant. The electrode impedance exponentially decreases with increase in frequency. The experiment was repeated on multiple subjects and with different electrode spacing of $25 \mathrm{~mm}$ and $30 \mathrm{~mm}$. The results were found to be repeatable. The type-I textile electrode was chosen for recording the bio-potential signals of ECG and EEG as its performance nearly matches with that of the wet and dry Ag-AgCl electrodes.

Figure 13 shows the photograph of the wearable system worn by an healthy individual showing the sensor nodes to acquire ECG, EEG, PPG, GSR and body temperature and sink node to transmit the acquired data to a remote monitoring station.

The wearable physiological monitoring system was worn by 35 subjects and the data was acquired for 


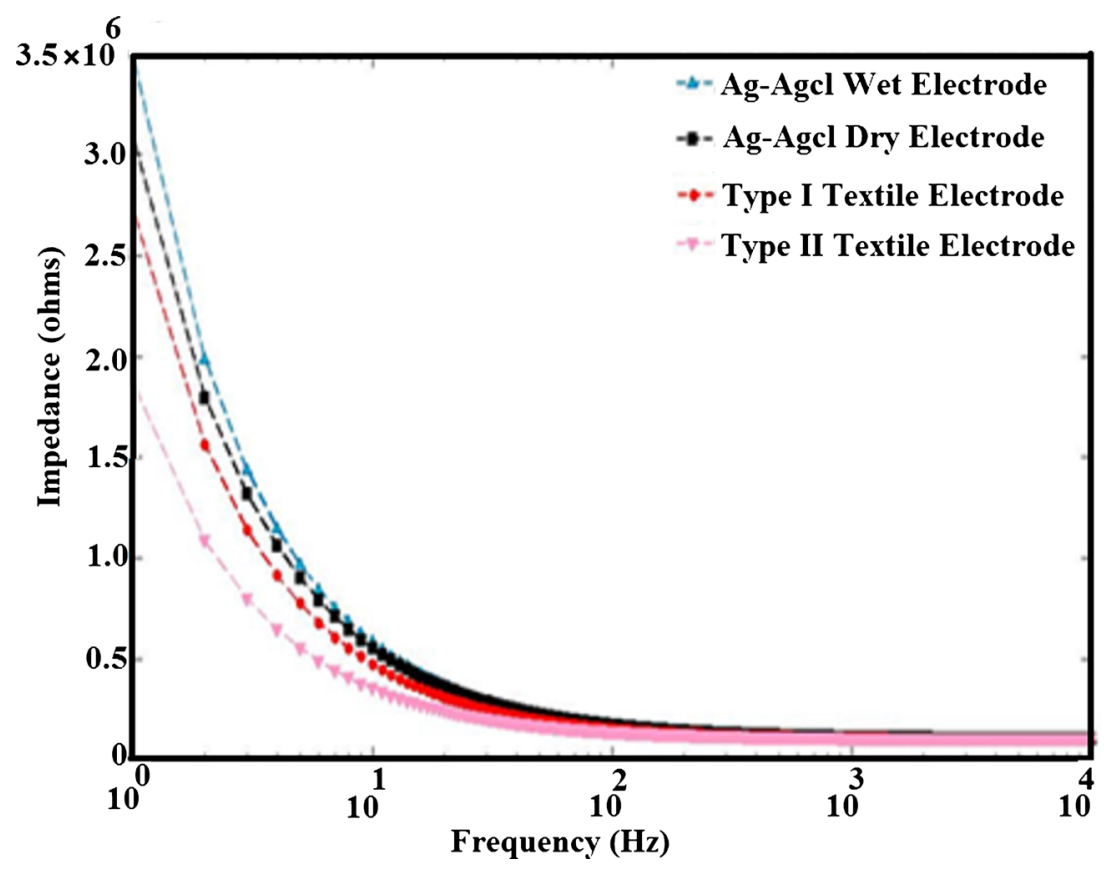

Figure 12. The skin-electrode contact impedance of different types of electrodes Ag-AgCl Wet Electrodes, $\mathrm{Ag}-\mathrm{AgCl}$ dry electrodes, Type-I textile electrode and Type-II textile electrode.

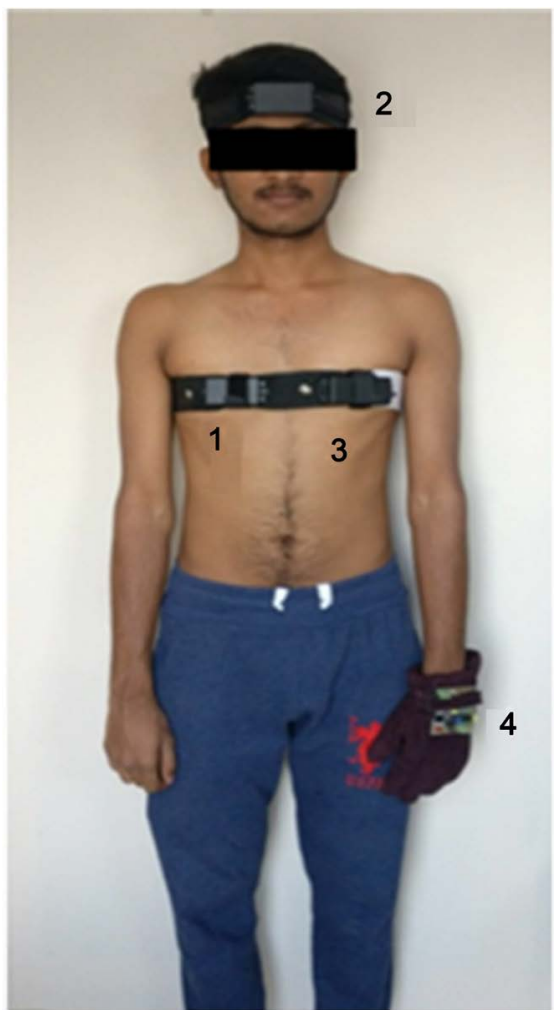

1-ECG Sensor Node, 2-EEG Sensor Node, 3-Sink Node and 4-PPG \& GSR Sensor Node.

Figure 13. Photograph of (a) Sensor Node 1 to acquire ECG (b) Sensor Node 2 to acquire EEG and (c) Sensor Node 3 to acquire PPG and GSR (d) Sink node to acquire signals from sensor nodes and transmit to remote monitoring station. 
interpretation and analysis, the subjects did not have any discomfort and difficulty wearing it for longer durations while performing their routine activity. Figure 14 shows the photograph of the textile electrode integrated in the belt to acquire bio-potential signal.

Figure 15(a) illustrates the raw ECG signal acquired corrupted with $50 \mathrm{~Hz}$ power line interference and Figure 15(b) illustrates the power line interference filtered ECG signal. The amplitude spectrum of the processed ECG signals shows that there is no power line interference present in the ECG signal.

The $50 \mathrm{~Hz}$ power line interference in ECG signal is removed $[49,50]$ by passing the signal through IIR-Notch, LMS filter \& DWT Filter. Different performance parameters like Magnitude coherence (MSC), signal to Noise Ratio (SNR), Power Spectral Density (PSD), Percentage root mean square difference (\%PRD), Mean Square Error (MSE) and Error standard Deviation (ESD) are calculated using the three

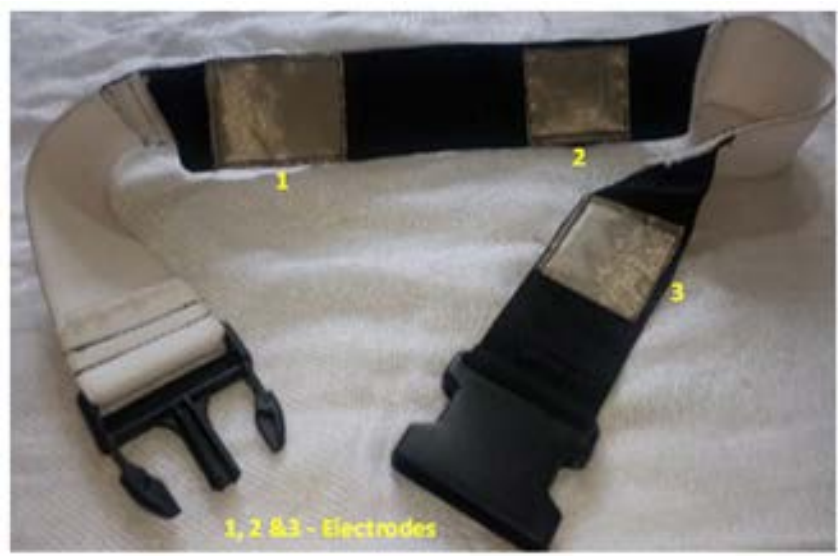

Figure 14. Textile electrode fabricated.

(a) Original ECG Signal

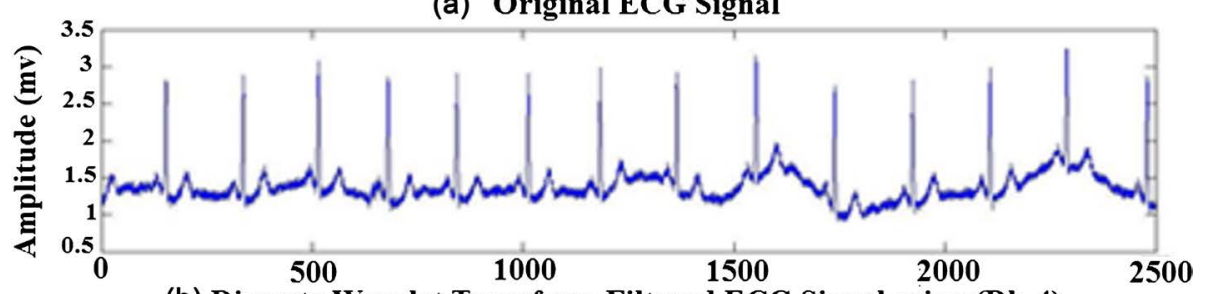

(b) Discrete Wavelet Transform Filtered ECG Signal using (Db-4)

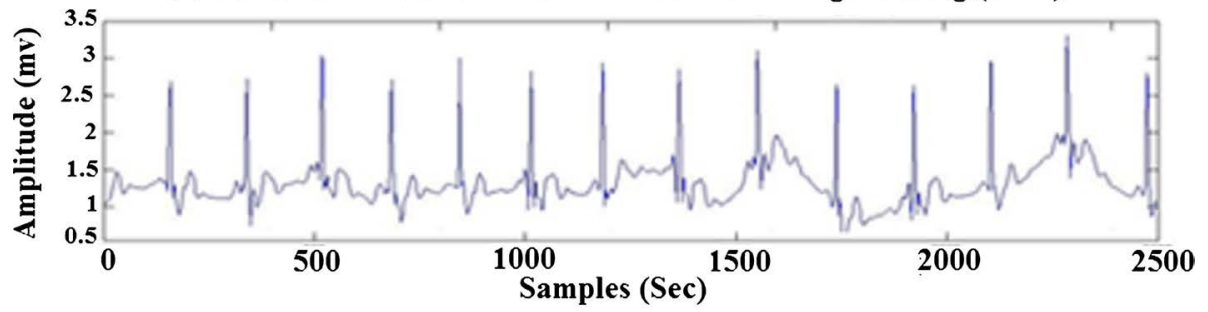

(c) Amplitude Spectrum of DWT Filtered ECG Signal

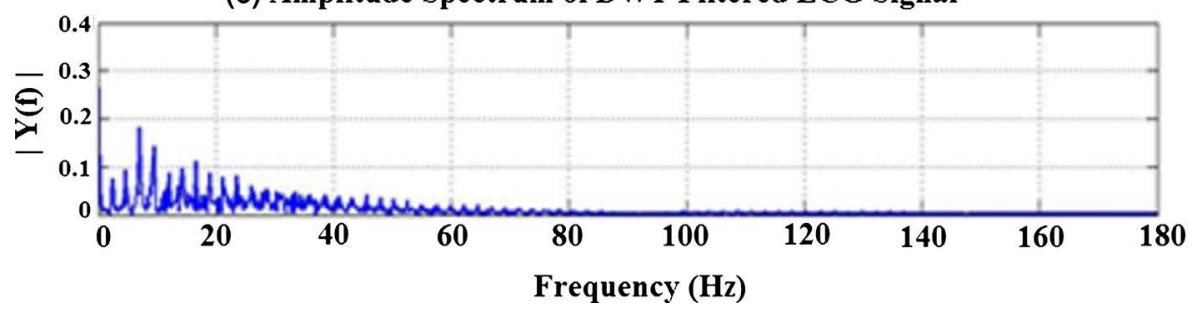

Figure 15. ECG Signal acquired from Node-1 (a) raw ECG signal (b) power line noise removed ECG signal using DWT filtering (c) Amplitude spectrum of the DWT filtered ECG signal. 
filtering techniques. From the evaluation of the above performance parameters we conclude that DWT filter is best for removing the $50 \mathrm{~Hz}$ power line interference noise compared to the other two types of filtering techniques.

The results evaluated for five subjects are as shown in Table 3.

Figure 16(a) illustrates the raw PPG signal and Figure 16(b) the power line interference removed PPG signal.

Table 3. Performance parameters Estimation from the original ECG signal.

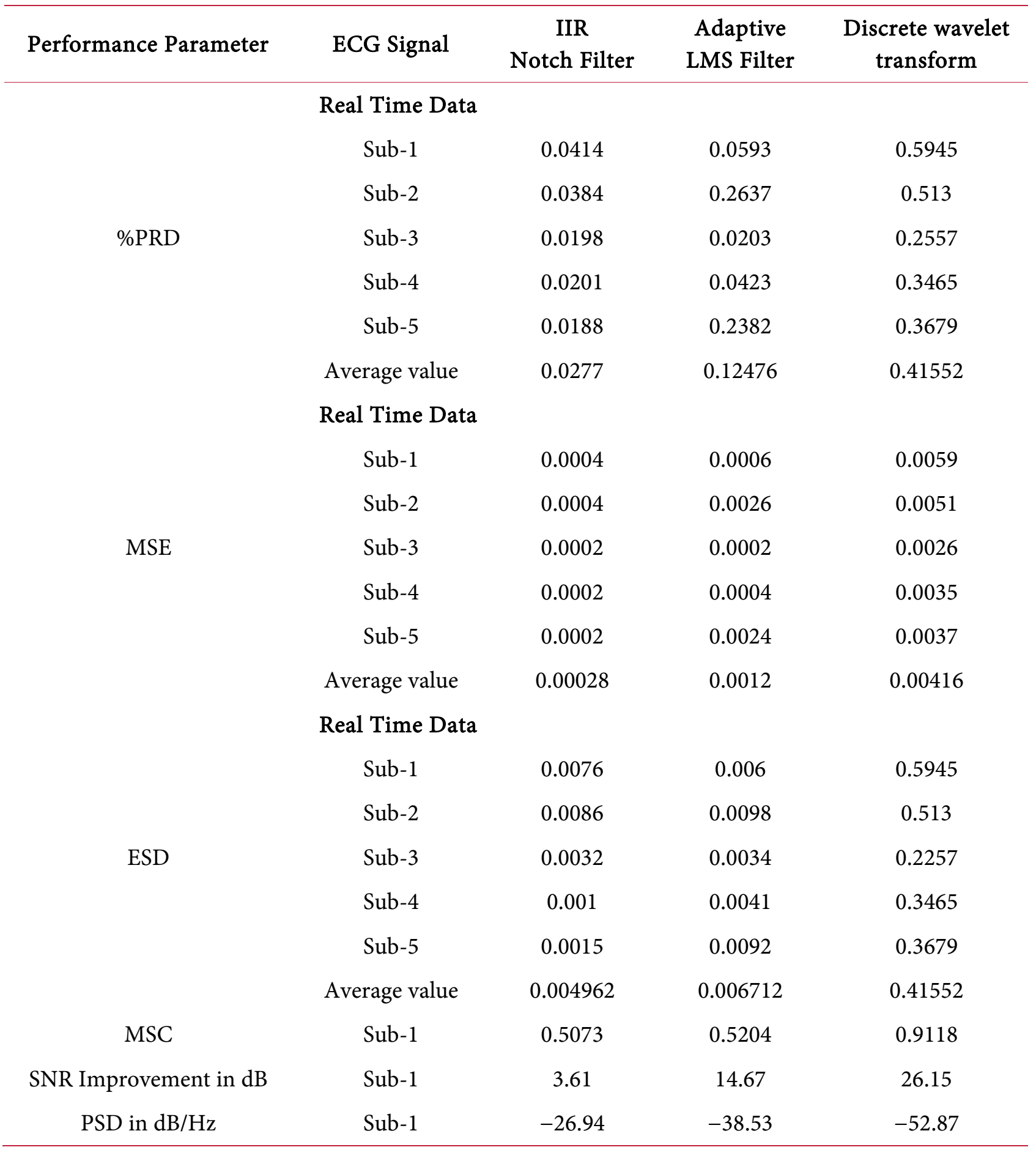


The amplitude spectrum of the PPG signal has confirmed the absence of power line interference in the PPG signals. Figure 17 illustrates the ECG signal acquired from ECG sensor node while the subject was performing routine activity, the raw signal Figure $17(\mathrm{a})$ is corrupted with noises such as baseline wander and tremor noises, the baseline wander is removed by Kaiser high pass filter as shown in Figure 17(b) and the tremors removed by Kaiser low pass filter as shown in Figure 17(c). The processed ECG signal is noise free and is of diagnostic quality.

Figure 18 illustrates the EEG signal acquired from sensor node-2 to acquire EEG signal from the frontal pole regions fp1-fp2, while the subject performed routine activity. The EEG acquired from conventional

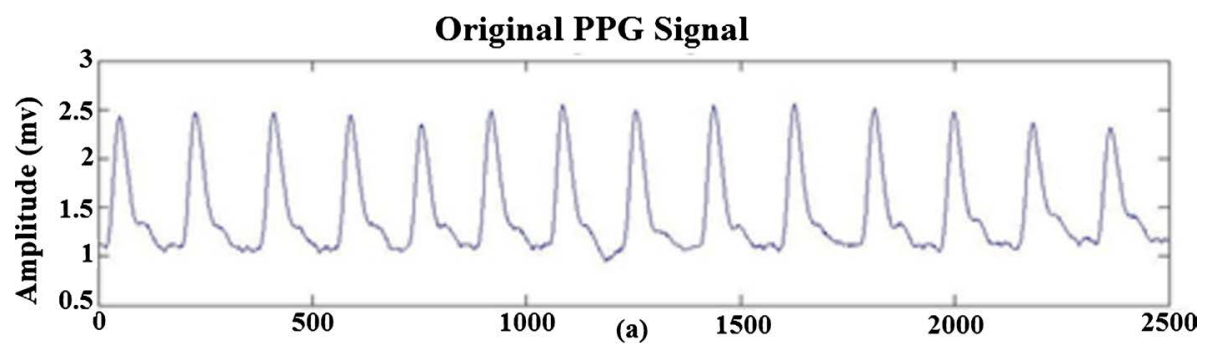

Discrete Wavelet Transform Filtered PPG Signal using (Db-4)

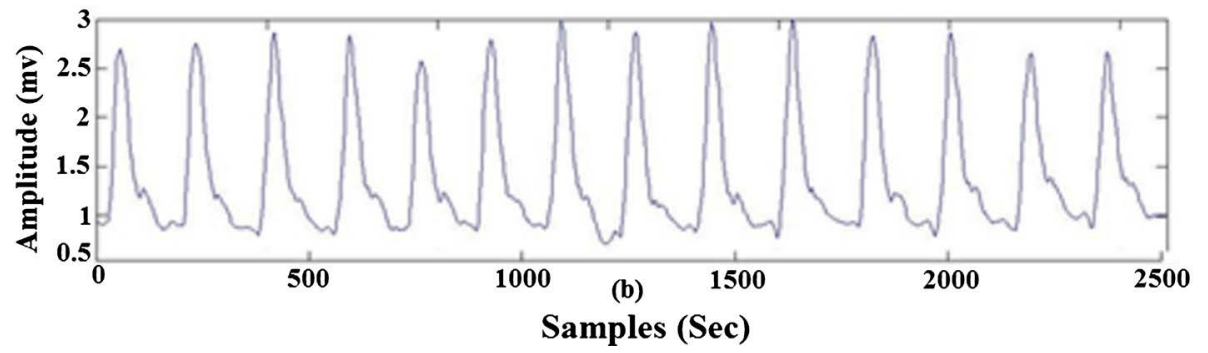

Figure 16. PPG Signal acquired from Node-3 (a) raw PPG signal (b) processed PPG signal after removal of power line interference.
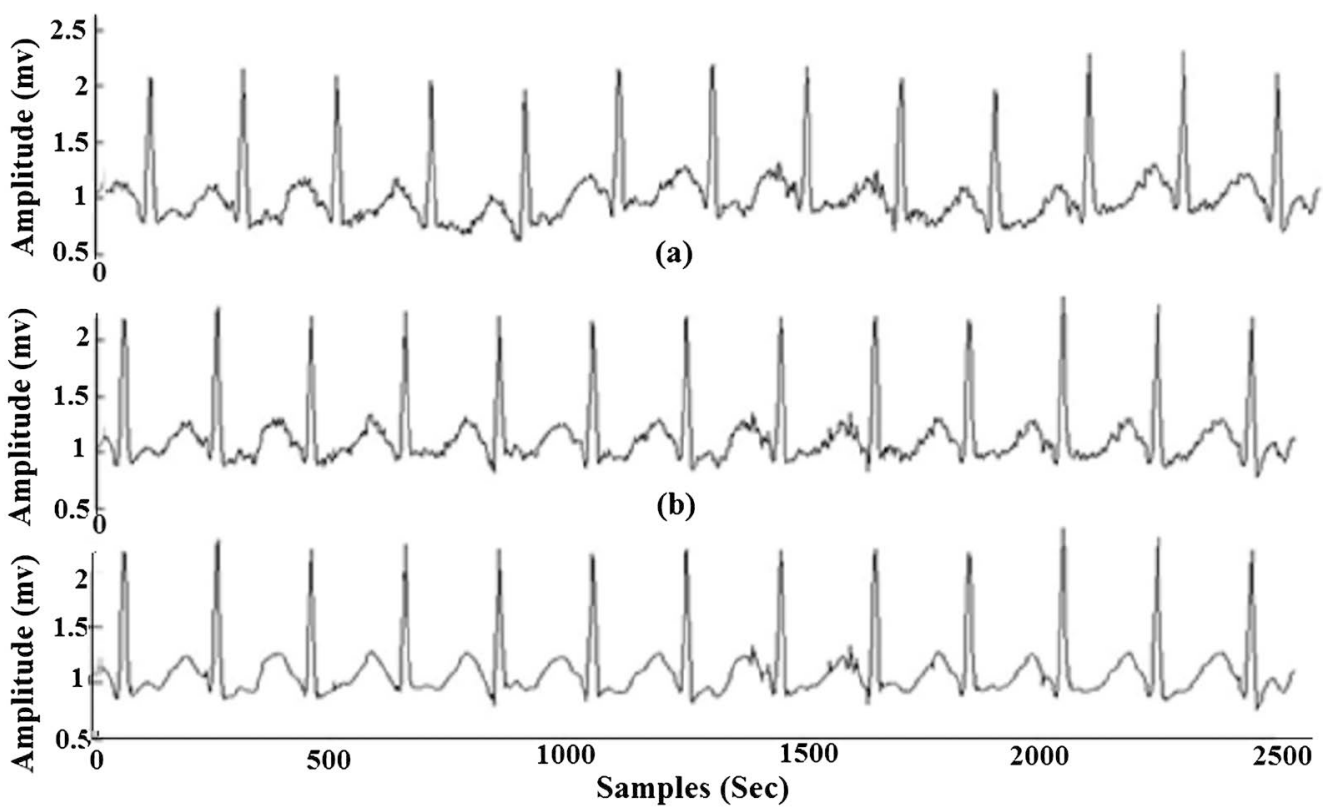

(c)

Figure 17. ECG Signal acquired from Node-1, (a) raw ECG signal (b) baseline wander removed (c) tremor removed ECG signal. 

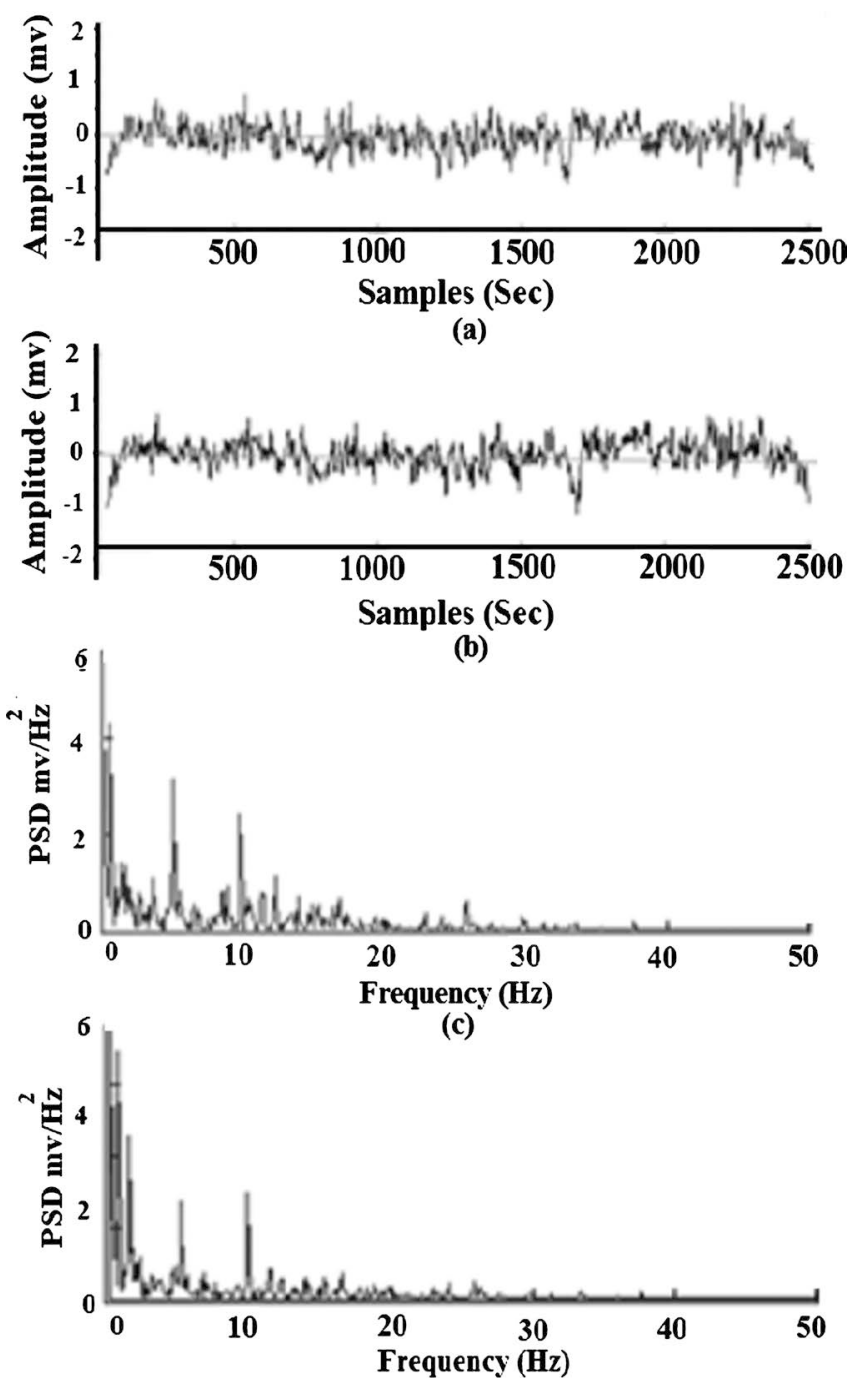

(d)

Figure 18. EEG Signal acquired from fp1-fp2 during the normal activity of the subject acquired from sensor Node-2 (a) from conventional Ag-AgCl electrode (b) dry textile electrode (c) Power Spectral Density (PSD) of Ag-AgCl electrode (d) Power Spectral density (PSD) of textile electrode.

$\mathrm{Ag}-\mathrm{AgCl}$ electrodes Figure 18(a) and the textile electrodes Figure 18(b) are comparable as it is evident from the power spectral density of the EEG signal acquired from $\mathrm{Ag}-\mathrm{AgCl}$ electrode Figure 18(c) and textile electrode Figure 18(d).

The GSR recordings from five subjects while performing predetermined tasks such as relaxing, deep breathing, reading and performing mathematical operations are shown in Figure 19.

From the GSR recordings it is evident the GSR is low when the subjects are relaxed and the conductance increases while they performed mathematical operations. The skin temperature recordings from five subjects while performing predetermined tasks such as resting, walking, exercise and recovery are shown in Figure 20.

From the body temperature, recordings it is evident that it is low when the subjects are resting and the skin temperature increases when they performed mild exercise and decreases during recovery stages. Table 4 shows the data of heart rate and blood pressure acquired from 34 subjects using conventional $\mathrm{BP}$ machine and wearable monitoring system while performing routine activity during resting, walking and mild exercise conditions. 


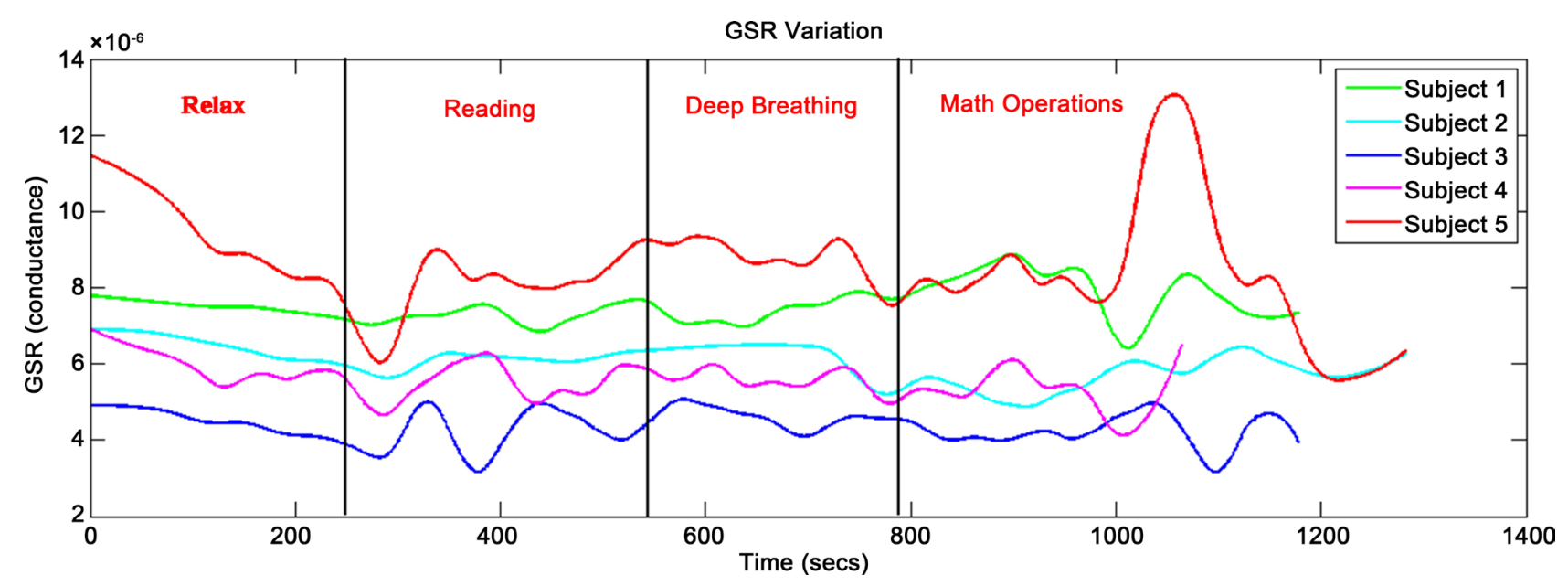

Figure 19. GSR signal acquired from Node-3 for five subjects during relaxed, reading, deep breathing and while performing Mathematical operations.

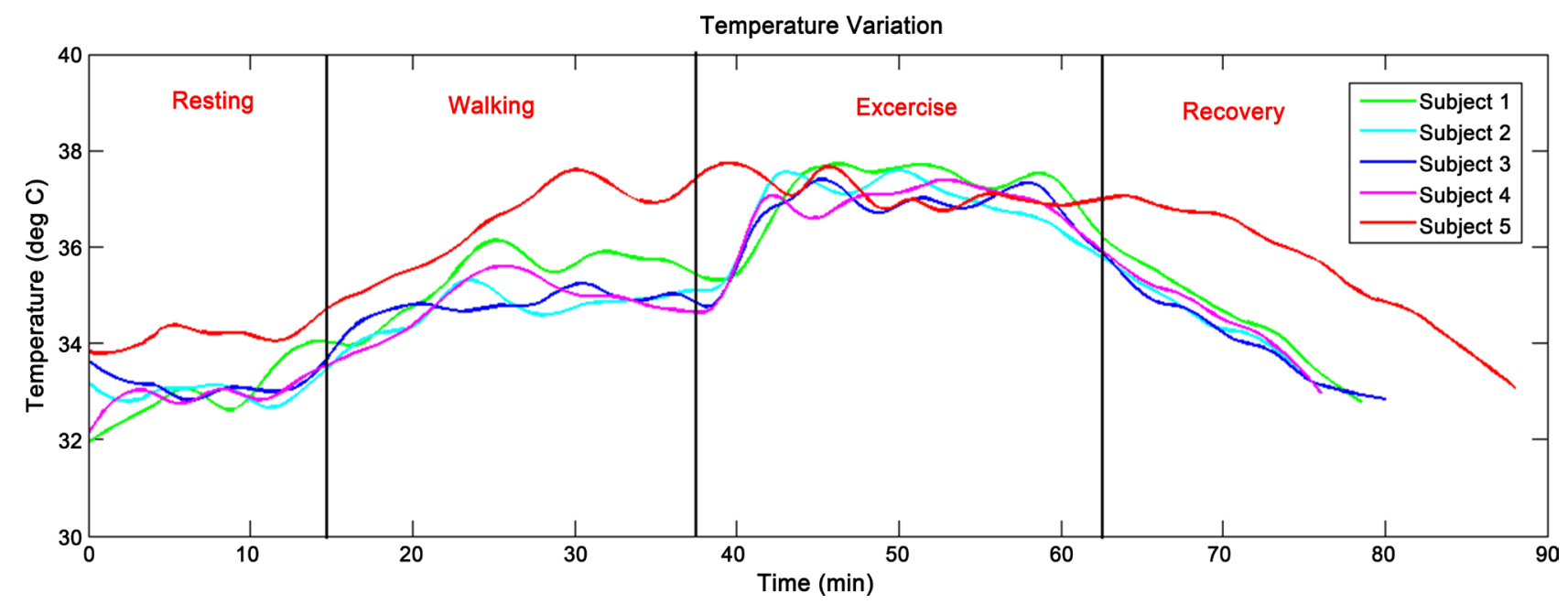

Figure 20. Skin temperature recording from Node-1 for 5 subjects during resting, walking, Exercise \& Recovery stages.

The statistical analysis of the vital parameters of heart rate and blood pressure recorded from the developed prototype were compared with that acquired using a standard measurement device. In the proposed work we have tested our system with 34 subjects with 10 average readings i.e. 340 readings have been taken from the subjects for each condition. All the above subjects were subjected to different conditions. First the HR, SBP, DBP were merured with the standard instruments with the help of doctor, then we tested the above readings with our system using the equations developed for SBP, DBP. Table 4 shows the readings of comparison.

The bias and precision for heart rate recorded from the developed wearable systems and standard measurement method while the subjects were performing the routine activity of resting, walking and mild exercise are measured. The bias for heart rate measured during resting, walking and mild exercise was $0.0028,0.00035 \&-0.000056$ respectively. The precision for heart rate measured during resting, walking and mild exercise was $0.8231,0.9325 \& 0.9272 \mathrm{bpm}$ respectively. The Bland-Altman plots for heart rate while resting, walking and mild exercise are illustrated in Figure 21(a), Figure 21(b) and Figure 21(c) respectively.

The bias and precision for systolic blood pressure recorded from the developed wearable systems and 
Table 4. Heart Rate (HR), SBP, DBP of 34 subjects measured during resting, walking and exercise conditions.

\begin{tabular}{|c|c|c|c|c|c|c|c|c|c|c|c|}
\hline Subject & $\begin{array}{l}\text { Age } \\
\text { (Yrs) }\end{array}$ & $\begin{array}{c}\text { HR } \\
\text { Std } \\
\text { (bpm) }\end{array}$ & $\begin{array}{c}\mathrm{RR} \\
\text { Interval } \\
\text { from ECG } \\
(\mathrm{msec})\end{array}$ & $\begin{array}{c}\text { HR from } \\
\text { ECG } \\
(\mathrm{bpm})\end{array}$ & $\begin{array}{c}\text { Wt } \\
\text { (Kgs) }\end{array}$ & $\begin{array}{c}\mathrm{Ht} \\
(\mathrm{Cms})\end{array}$ & $\begin{array}{c}\text { SBP } \\
\text { Measured } \\
(\mathrm{mmHg})\end{array}$ & $\begin{array}{c}\text { DBP } \\
\text { Measured } \\
(\mathrm{mmHg})\end{array}$ & $\begin{array}{c}\text { PTT } \\
\text { (msec) }\end{array}$ & $\begin{array}{c}\text { SBP } \\
\text { Derived } \\
(\mathrm{mmHg})\end{array}$ & $\begin{array}{c}\text { DBP } \\
\text { Derived } \\
(\mathrm{mmHg})\end{array}$ \\
\hline 1 & 43 & $84 \pm 3$ & $0.71 \pm 0.03$ & $84 \pm 3.8$ & 64 & 167 & $130 \pm 3.08$ & $89 \pm 3.14$ & $57.6 \pm 0.36$ & $132.4 \pm 1.17$ & $97.4 \pm 2.72$ \\
\hline 2 & 53 & $75 \pm 4$ & $0.81 \pm 0.04$ & $75 \pm 5.1$ & 59 & 175 & $118 \pm 3.68$ & $80 \pm 3.94$ & $60 \pm 0.32$ & $127.4 \pm 1.35$ & $95.6 \pm 2.07$ \\
\hline 3 & 54 & $81 \pm 3$ & $0.74 \pm 0.03$ & $81 \pm 5.5$ & 49 & 160 & $137 \pm 4.42$ & $84 \pm 3.23$ & $58 \pm 0.19$ & $132.3 \pm 1.06$ & $96.9 \pm 2.6$ \\
\hline 4 & 81 & $90 \pm 2$ & $0.66 \pm 0.02$ & $91 \pm 4.2$ & 75 & 154 & $157 \pm 2.83$ & $94 \pm 3.13$ & $49.8 \pm 0.25$ & $150.1 \pm 0.74$ & $99.5 \pm 2.46$ \\
\hline 5 & 25 & $70 \pm 3$ & $0.86 \pm 0.04$ & $70 \pm 4.9$ & 52 & 178 & $97 \pm 2.42$ & $64 \pm 2.31$ & $76.6 \pm 0.31$ & $112.9 \pm 1.29$ & $92.4 \pm 2.22$ \\
\hline 6 & 58 & $77 \pm 4$ & $0.78 \pm 0.04$ & $77 \pm 4.9$ & 60 & 162 & $132 \pm 2.04$ & $85 \pm 3.26$ & $66.7 \pm 0.23$ & $130.7 \pm 1.16$ & $95.2 \pm 2.53$ \\
\hline 7 & 75 & $90 \pm 4$ & $0.66 \pm 0.03$ & $91 \pm 5.1$ & 85 & 155 & $144 \pm 3.6$ & $91 \pm 3.01$ & $59.4 \pm 0.22$ & $147.4 \pm 1.35$ & $98.2 \pm 1.99$ \\
\hline 8 & 46 & $90 \pm 4$ & $0.66 \pm 0.03$ & $91 \pm 4.1$ & 78 & 172 & $138 \pm 2.47$ & $76 \pm 2.9$ & $60 \pm 0.27$ & $135.6 \pm 1.35$ & $97.8 \pm 2.53$ \\
\hline 9 & 80 & $99 \pm 3$ & $0.6 \pm 0.02$ & $100 \pm 5.9$ & 82 & 151 & $160 \pm 2.9$ & $101 \pm 2.67$ & $45.5 \pm 0.26$ & $156.3 \pm 1.06$ & $101.5 \pm 2.92$ \\
\hline 10 & 45 & $78 \pm 4$ & $0.77 \pm 0.04$ & $78 \pm 5.4$ & 52 & 150 & $130 \pm 2.42$ & $82 \pm 2.28$ & $68.4 \pm 0.33$ & $129.3 \pm 1.16$ & $95.1 \pm 2.23$ \\
\hline 11 & 60 & $90 \pm 2$ & $0.66 \pm 0.02$ & $91 \pm 3.5$ & 65 & 158 & $136 \pm 1.85$ & $84 \pm 1.91$ & $59.4 \pm 0.33$ & $139.8 \pm 0.79$ & $98.1 \pm 2.6$ \\
\hline 12 & 62 & $90 \pm 2$ & $0.66 \pm 0.01$ & $90 \pm 5.7$ & 62 & 156 & $138 \pm 2.67$ & $86 \pm 2.73$ & $52.3 \pm 0.32$ & $142.2 \pm 0.79$ & $99.1 \pm 2.6$ \\
\hline 13 & 64 & $67 \pm 4$ & $0.91 \pm 0.05$ & $66 \pm 4.9$ & 70 & 161 & $129 \pm 2.49$ & $84 \pm 3.27$ & $48.2 \pm 0.29$ & $136.8 \pm 1.23$ & $95.9 \pm 2.13$ \\
\hline 14 & 62 & $86 \pm 2$ & $0.69 \pm 0.02$ & $86 \pm 4.8$ & 78 & 158 & $135 \pm 2.69$ & $96 \pm 3.27$ & $53.8 \pm 0.21$ & $143.1 \pm 0.88$ & $98.1 \pm 2.56$ \\
\hline 15 & 70 & $74 \pm 2$ & $0.81 \pm 0.03$ & $74 \pm 4.3$ & 55 & 159 & $135 \pm 3$ & $80 \pm 2.7$ & $52.7 \pm 0.27$ & $136.7 \pm 0.67$ & $96.6 \pm 2.12$ \\
\hline 16 & 62 & $90 \pm 3$ & $0.66 \pm 0.02$ & $91 \pm 4.3$ & 60 & 170 & $138 \pm 2.9$ & $82 \pm 3.7$ & $49.5 \pm 0.3$ & $139.5 \pm 1.18$ & $99.5 \pm 2.76$ \\
\hline 17 & 51 & $67 \pm 2$ & $0.9 \pm 0.03$ & $67 \pm 5.7$ & 49 & 155 & $115 \pm 3.13$ & $83 \pm 2.33$ & $68 \pm 0.29$ & $125.1 \pm 0.88$ & $93.1 \pm 2.08$ \\
\hline 18 & 65 & $86 \pm 4$ & $0.7 \pm 0.03$ & $86 \pm 3.5$ & 60 & 152 & $140 \pm 2.38$ & $90 \pm 3.18$ & $52.9 \pm 0.35$ & $141.9 \pm 1.37$ & $98.6 \pm 2.99$ \\
\hline 19 & 68 & $88 \pm 4$ & $0.68 \pm 0.03$ & $89 \pm 4.4$ & 55 & 148 & $156 \pm 2.18$ & $81 \pm 3.58$ & $52.3 \pm 0.24$ & $143.6 \pm 1.26$ & $99.1 \pm 2.51$ \\
\hline 20 & 68 & $86 \pm 3$ & $0.69 \pm 0.02$ & $86 \pm 4.3$ & 60 & 151 & $136 \pm 4.06$ & $86 \pm 3.46$ & $53.8 \pm 0.3$ & $142.6 \pm 1.26$ & $98.4 \pm 2.17$ \\
\hline 21 & 42 & $77 \pm 2$ & $0.78 \pm 0.02$ & $77 \pm 3.8$ & 58 & 156 & $116 \pm 1.91$ & $83 \pm 2.97$ & $64.8 \pm 0.26$ & $129.2 \pm 0.63$ & $95.4 \pm 2.32$ \\
\hline 22 & 60 & $96 \pm 4$ & $0.62 \pm 0.03$ & $97 \pm 5.4$ & 65 & 149 & $150 \pm 2.15$ & $90 \pm 3.25$ & $52.9 \pm 0.25$ & $146.2 \pm 1.48$ & $100.3 \pm 3.06$ \\
\hline 23 & 34 & $78 \pm 3$ & $0.77 \pm 0.04$ & $78 \pm 4.5$ & 53 & 164 & $122 \pm 2.1$ & $81 \pm 1.99$ & $59.6 \pm 0.25$ & $126.8 \pm 1.03$ & $96.1 \pm 2.69$ \\
\hline 24 & 60 & $84 \pm 2$ & $0.71 \pm 0.02$ & $84 \pm 6$ & 49 & 151 & $136 \pm 4.14$ & $84 \pm 3.75$ & $62.3 \pm 0.3$ & $135.5 \pm 0.71$ & $96.8 \pm 2.97$ \\
\hline 25 & 83 & $99 \pm 2$ & $0.6 \pm 0.01$ & $100 \pm 3.7$ & 80 & 148 & $169 \pm 3.45$ & $95 \pm 3.3$ & $38.3 \pm 0.32$ & $159.8 \pm 0.63$ & $102.6 \pm 2.88$ \\
\hline 26 & 87 & $96 \pm 3$ & $0.62 \pm 0.02$ & $97 \pm 4.8$ & 90 & 149 & $178 \pm 3.21$ & $95 \pm 4.01$ & $32.7 \pm 0.4$ & $163 \pm 1.05$ & $102.6 \pm 2.5$ \\
\hline 27 & 76 & $98 \pm 3$ & $0.6 \pm 0.02$ & $99 \pm 4.8$ & 2 & 159 & $152 \pm 2.6$ & $88 \pm 2.85$ & $57.6 \pm 0.25$ & $143.4 \pm 1.17$ & $99.9 \pm 3.41$ \\
\hline 28 & 71 & $90 \pm 3$ & $0.66 \pm 0.03$ & $91 \pm 4.9$ & 0 & 143 & $150 \pm 2.18$ & $90 \pm 3.95$ & $57.5 \pm 0.39$ & $145.4 \pm 1.26$ & $98.7 \pm 2.98$ \\
\hline 29 & 26 & $68 \pm 2$ & $0.89 \pm 0.02$ & $68 \pm 4$ & 51 & 175 & $91 \pm 2.1$ & $61 \pm 3.57$ & $78.2 \pm 0.26$ & $112.2 \pm 0.63$ & $91.9 \pm 2.18$ \\
\hline 30 & 45 & $78 \pm 2$ & $0.77 \pm 0.02$ & $78 \pm 4.6$ & 60 & 164 & $138 \pm 2.11$ & $90 \pm 2$ & $56.7 \pm 0.27$ & $131.1 \pm 0.88$ & $96.4 \pm 2.12$ \\
\hline 31 & 55 & $78 \pm 3$ & $0.77 \pm 0.03$ & $78 \pm 5.5$ & 68 & 160 & $140 \pm 2.53$ & $90 \pm 1.91$ & $56.6 \pm 0.4$ & $135.7 \pm 1.06$ & $96.4 \pm 1.78$ \\
\hline 32 & 53 & $85 \pm 2$ & $0.7 \pm 0.02$ & $85 \pm 3.8$ & 70 & 165 & $144 \pm 2.1$ & $86 \pm 3.19$ & $59.2 \pm 0.33$ & $135.7 \pm 0.67$ & $97.2 \pm 2.2$ \\
\hline 33 & 54 & $80 \pm 4$ & $0.75 \pm 0.04$ & $80 \pm 5.8$ & 75 & 166 & $148 \pm 3$ & $92 \pm 2.44$ & $57.9 \pm 0.37$ & $135.5 \pm 1.18$ & $96.6 \pm 1.84$ \\
\hline 34 & 60 & $88 \pm 3$ & $0.68 \pm 0.02$ & $89 \pm 5.2$ & 70 & 160 & $148 \pm 1.91$ & $96 \pm 2.78$ & $53.8 \pm 0.28$ & $141.4 \pm 1.07$ & $98.7 \pm 2.58$ \\
\hline
\end{tabular}




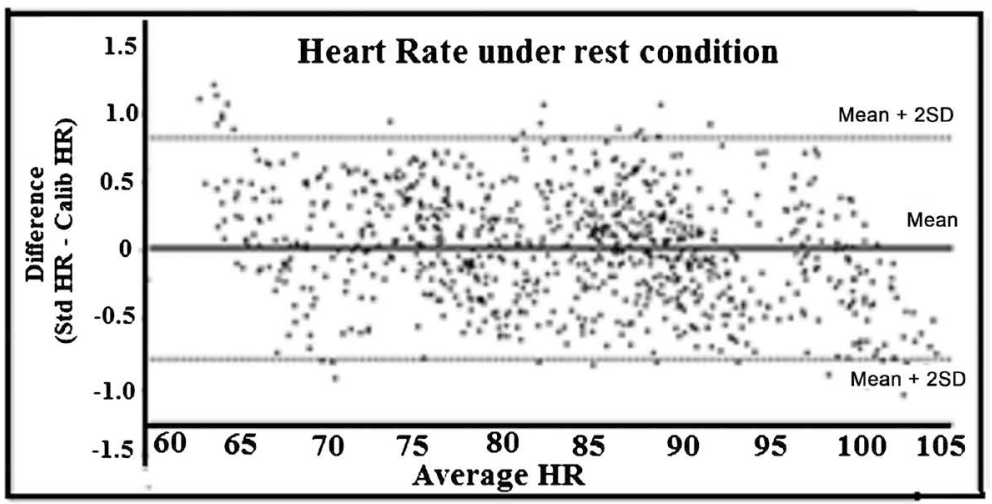

(a)

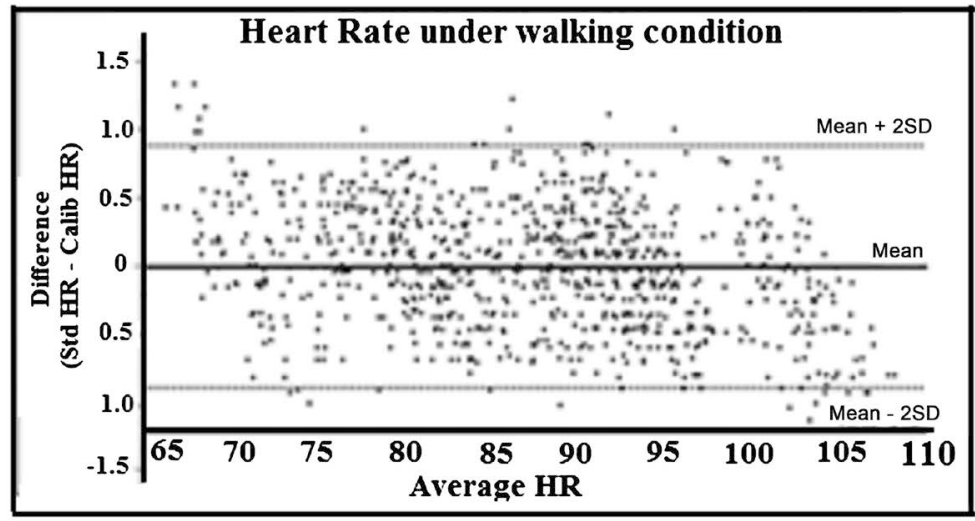

(b)

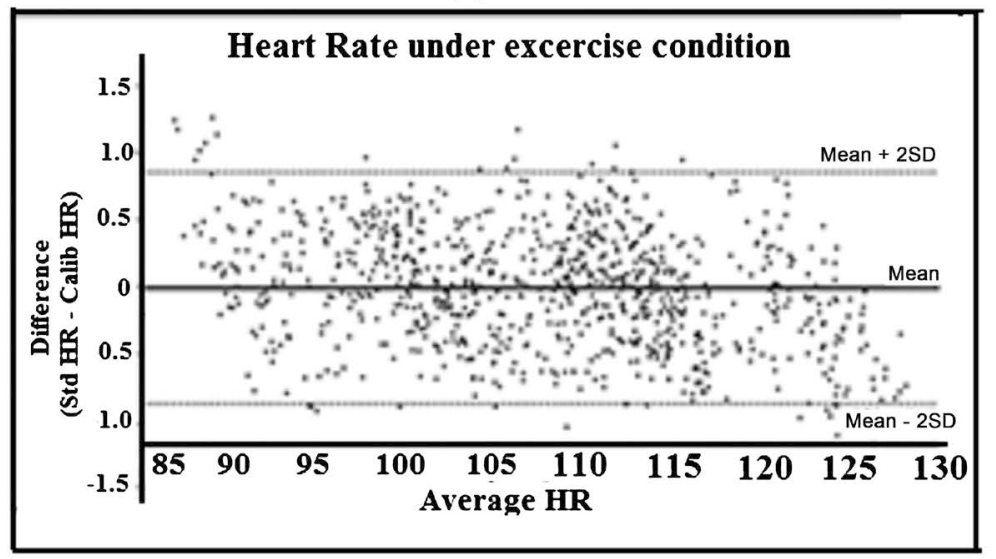

(c)

Figure 21. Bland-Altman plots for Heart Rate comparison from 34 subjects during (a) resting (b) walking (c) exercise conditions. The limits of agreement defined by $2 \mathrm{SD}$ above and below the bias are shown by dotted lines.

standard measurement method while the subjects were performing the routine activity of resting, walking and mild exercise are measured. The bias for systolic blood pressure measured during resting, walking and mild exercise was $-0.00045,0.00024 \& 0.00024$ respectively. The precision for systolic blood pressure measured during resting, walking and mild exercise was 5.8123, $5.1233 \& 6.8934$ respectively.

The Bland-Altman plots for systolic blood pressure while resting, walking and mild exercise are illustrated in Figure 22(a), Figure 22(b) and Figure 22(c) respectively.

The bias and precision for diastolic blood pressure recorded from the developed wearable systems 


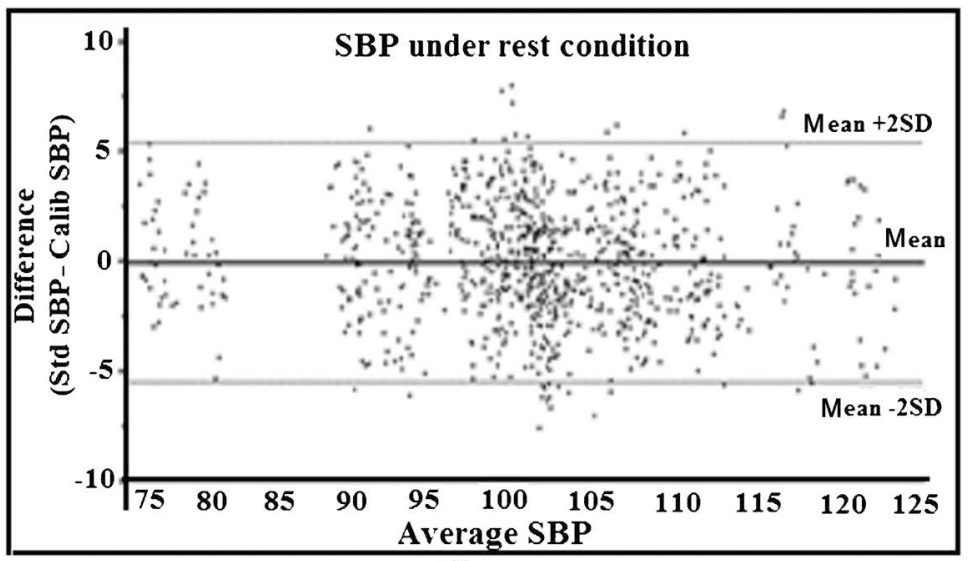

(a)

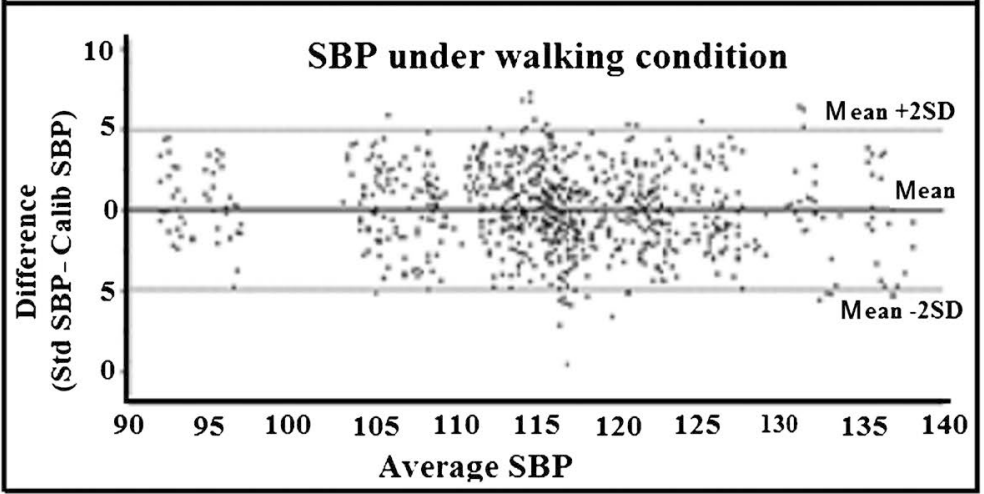

(b)

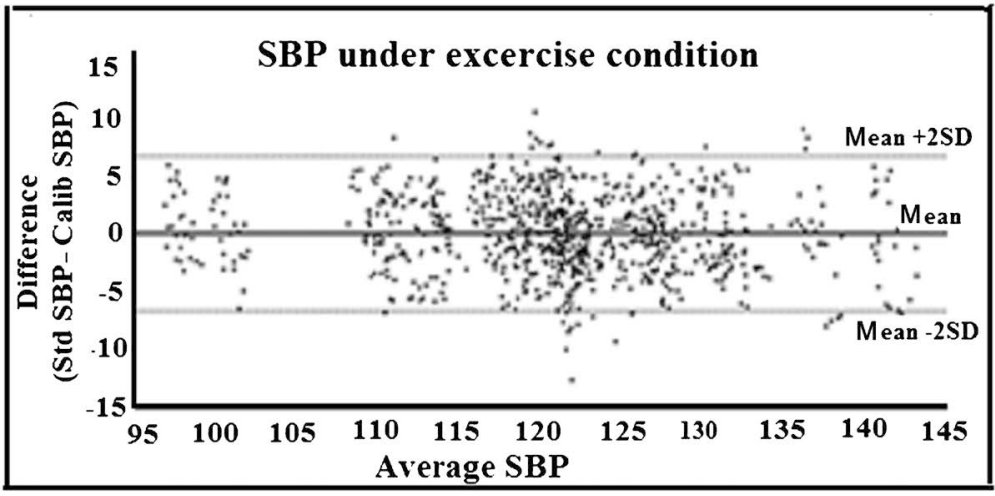

(c)

Figure 22. Bland-Altman plot for Systolic Blood Pressure comparison from 34 subjects during (a) resting (b) walking (c) exercise conditions. The limits of agreement defined by 2S.D above and below the bias are shown by dotted lines.

and standard measurement method while the subjects were performing the routine activity of resting, walking and mild exercise are measured. The bias for diastolic blood pressure measured during resting, walking and mild exercise was $0.00012,0.00341 \& 0.00014$ respectively. The precision for diastolic blood pressure measured during resting, walking and mild exercise was $4.9756,4.8745 \& 4.9945$ respectively. The accuracy of the system is within the limits of IEEE Standard of $(5 \pm 8 \mathrm{mmHg})$.

The Bland-Altman plots for diastolic blood pressure while resting, walking and mild exercise are illustrated in Figure 23(a), Figure 23(b) and Figure 23(c) respectively.

Figure 24(a) illustrates the time domain plot of the R-R intervals for 1-hour duration of heart rate 


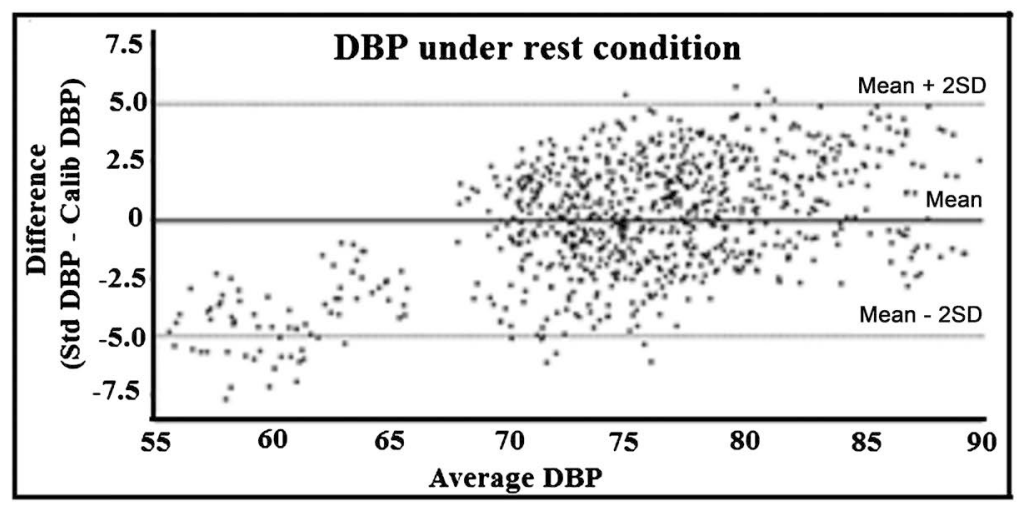

(a)

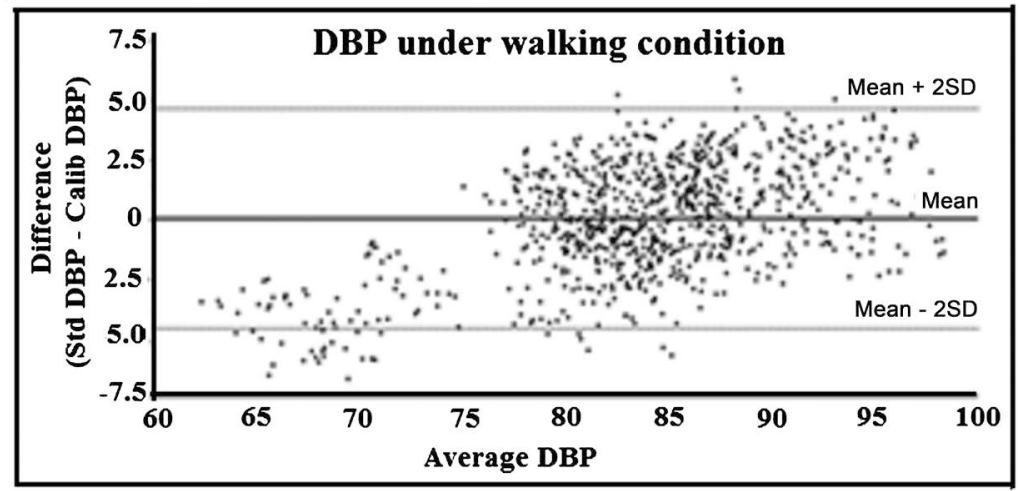

(b)

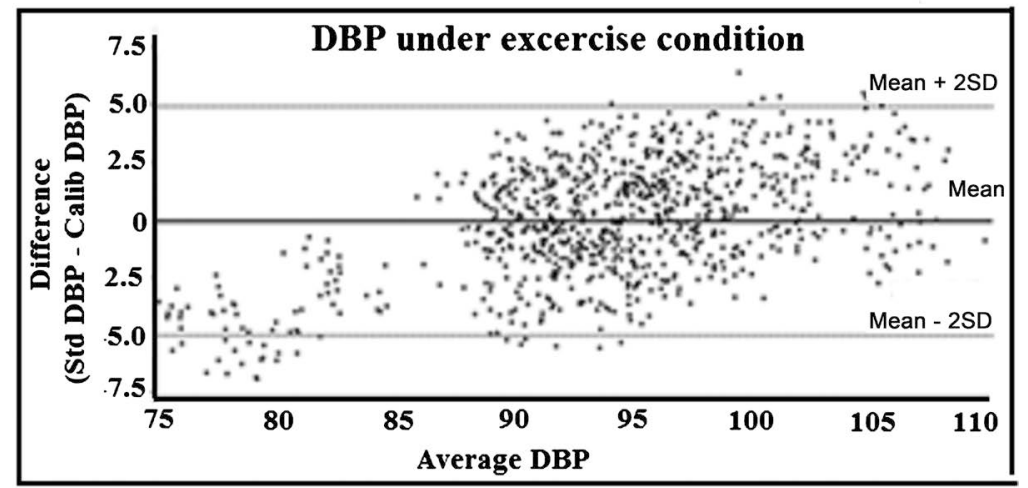

(c)

Figure 23. Bland-Altman plot for Diastolic Blood Pressure comparison from 34 subjects during (a) resting (b) walking (c) exercise conditions. The limits of agreement defined by $2 \mathrm{SD}$ above and below the bias are shown by dotted lines.

measured from a healthy individual while the subject was performing normal routine activities and Figure 24(b) the RR interval distribution for the same subject recorded.

The time domain parameters calculated for a normal subject during resting, walking and mild exercise and the results are shown in Table 5. The mean RR was measured to be $796.59 \mathrm{msec}$, minimum and maximum heart rate was 64.69 and $86.44 \mathrm{bpm}$. The SDNN is $54.02 \mathrm{msec}$, RMSSD is $61.15 \mathrm{msec}$ and SDSD is $52.01 \mathrm{msec}$.

Table 6 illustrates the frequency domain parameters of HRV and the output gives the information about power distribution of spectral components obtained from RR intervals, the ULF, VLF, LF and HF measured are $0.003,0.003-0.04,0.04-0.15,0.15-0.4 \mathrm{~Hz}$ respectively. 


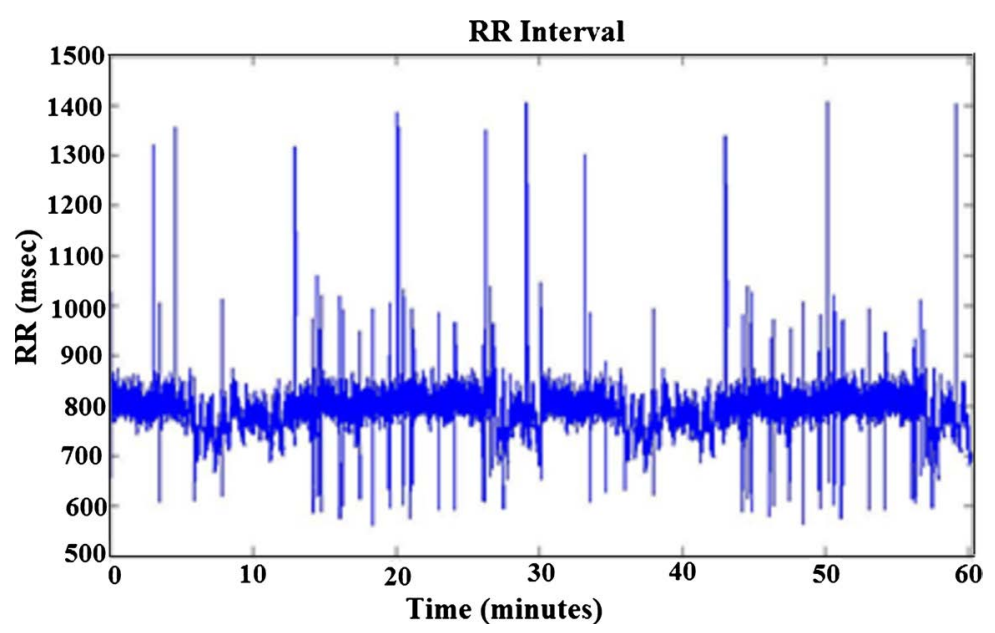

(a)

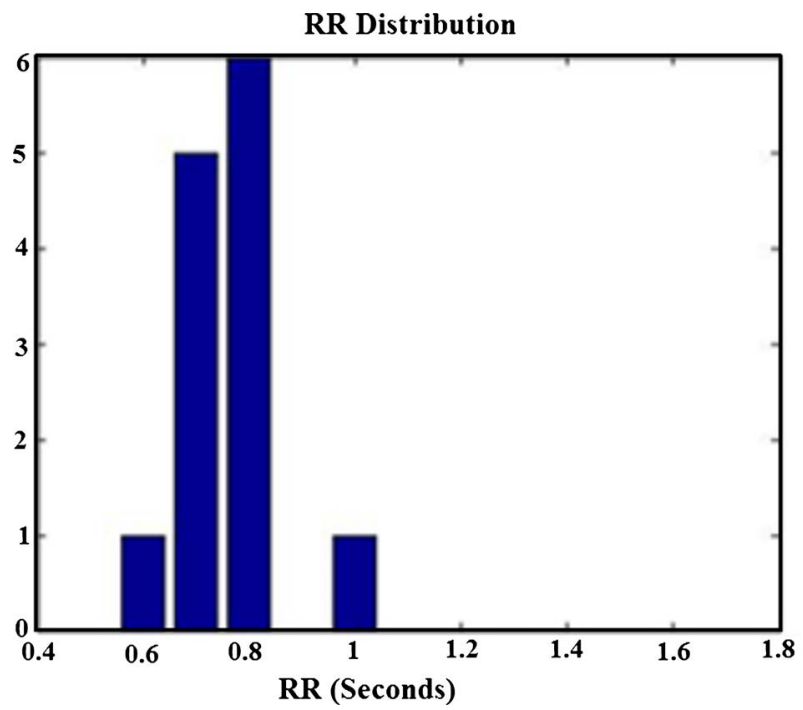

(b)

Figure 24. (a) Time domain plot of RR-Intervals for 1 hour Duration; (b) RR Interval distribution.

Table 5. HRV Time Domain parameters.

\begin{tabular}{cccc}
\hline SL. No & Parameters & Units & Results \\
\hline 1 & Mean RR & msec & 796.59 \\
2 & Mean HR & bpm & 75.32 \\
3 & Min HR & bpm & 64.69 \\
4 & Max HR & bpm & 86.44 \\
5 & SDNN & msec & 54.02 \\
6 & RMSSD & msec & 61.15 \\
7 & NN50 & beats & 484 \\
8 & pNN50 & $\%$ & 10.68 \\
9 & SDSD & msec & 52.01 \\
\hline
\end{tabular}


The LF, HF components and also the LF/HF ratio are used to indicate the stress or fatigue level of the subject under test and the approximate correlation between time and frequency domain evaluation parameters are illustrated in Table 7.

The power of all the four spectral power components is as shown in Table 8.

The nonlinear HRV values of SD1 and SD2 are represented in Table 9.

\section{Table 6. Frequency Domain parameters of HRV.}

\begin{tabular}{cccc}
\hline SL. No & Parameters & Description & Frequency range \\
\hline 1 & ULF & Power in ultra-low frequency $\left(\mathrm{ms}^{2}\right)$ & $0.003 \mathrm{~Hz}$ \\
2 & VLF & Power in very-low frequency $\left(\mathrm{ms}^{2}\right)$ & $0.003-0.04 \mathrm{~Hz}$ \\
3 & LF & Power in low frequency $\left(\mathrm{ms}^{2}\right)$ & $0.04-0.15 \mathrm{~Hz}$ \\
4 & HF & Power in high frequency $\left(\mathrm{ms}^{2}\right)$ & $0.15-0.4 \mathrm{~Hz}$ \\
\hline
\end{tabular}

Table 7. Correlation between Time Domain and Frequency Domain parameters of HRV.

\begin{tabular}{ccc}
\hline SL. No & Time domain Parameters & Frequency domain Parameters \\
\hline 1 & SDNN & Total Power \\
2 & RMSSD & HF \\
3 & SDSD & HF \\
4 & NN50 Count & HF \\
5 & pNN50 & HF \\
\hline
\end{tabular}

Table 8. Power of frequency Domain Components.

\begin{tabular}{cccccc}
\hline SL. No & Parameters & Units & VLF & LF & HF \\
\hline 1 & Frequency band & $\mathrm{Hz}$ & $0-0.04$ & $0.04-0.15$ & $0.15-0.40$ \\
2 & Peak Frequency & $\mathrm{Hz}$ & 0.040 & 0.140 & 0.167 \\
3 & Power & $\left(\mathrm{ms}^{2}\right)$ & 57 & 490 & 1535 \\
4 & Power & $(\log )$ & 4.042 & 6.194 & 7.336 \\
5 & Total Power & $\left(\mathrm{ms}^{2}\right)$ & 2086 & & \\
6 & Total Power & $(\log )$ & 7.643 & & \\
7 & LF/HF ratio & - & 0.319 & & \\
\hline
\end{tabular}

Table 9. Nonlinear results of HRV using SD1 and SD2.

\begin{tabular}{cccc}
\hline SL. No & Parameters & Unit & Value \\
\hline 1 & SD1 & $(\mathrm{msec})$ & 43.1 \\
2 & SD2 & $(\mathrm{msec})$ & 50.9 \\
3 & SD2/SD1 & - & 1.181 \\
\hline
\end{tabular}




\section{CONCLUSIONS}

A prototype wireless sensor network based physiological monitoring system developed is aimed to give a proof of concept of a wearable system. In this development four types of electrodes were characterized and studied for its suitability to be used for wearable monitoring. From the bio-potential signal, recording it was found that the type- 2 textile electrode is having good conductivity and can be easily integrated into the fabric and is comfortable for long duration monitoring. For the development of the above prototype system including the design and development of the data acquisition hardware the authors have spent around 2000 USD.

The subjects have reported that the chest belt fabricated using MedTex 180 is very soft and it is very comfort to wear for longer durations also. The conductivity of the material will be still good even when the subjects start sweating during the exercise conditions.

The physiological signals like ECG, EEG, GSR, body temperature, heart rate and blood pressure recorded from the wearable system are compared with those acquired from the Standard devices. The recording of heart rate, body temperature, GSR and blood pressure was found to be reliable and repeatable and the errors were in the acceptable limits.

The beat-to-beat non-invasive blood pressure measurement by the PTT based method does agree well with the simultaneously measured systolic and diastolic blood pressure while the subject is performing routine activities, during static and dynamic conditions. The better accuracy obtained even during dynamic conditions due to acquisition of good quality ECG \& PPG signals and pre-processing to remove the baseline wander and motion artifacts in the signals, calibrations carried out considering various factors such as age, arm length, height, weight of the subject. The American Association for Medical Instrumentation (AAMI) recommends that the bias and precision have to be within $5 \mathrm{mmHg}$ and $8 \mathrm{mmHg}$ respectively. From the data recorded it found that for both systolic and diastolic blood pressures, the bias and precision as required by the AAMI standards are achieved under static and dynamic conditions of the subject. The few recordings were outside the upper and lower limits of agreement, which are due to errors while recording as other data points are not seen clustered nearby.

The wearable physiological monitoring systems are intended to be used during the mobile conditions of the subjects, the physiological signals recorded are corrupted with unwanted noises such as powerline interference, baseline wander and motion artifacts. They are removed by signal processing techniques.

The HRV derived from ECG, which is directly controlled by the autonomic nervous system is a promising indicator for real-time fatigue estimation that can be used in various applications for soldiers in a battlefield, drivers, pilots, etc. The classification system uses time domain, frequency domain and nonlinear HRV features in this study.

Innovations in science and technology have contributed to a tremendous growth in medical care. New technological advancements in MEMS and Nanotechnology will play a major role in the future healthcare device development. In future, wearable devices will become affordable and available to use with minimal training.

There is a need to design wearable and smart sensors that are reliable and can give repeatable results without adding noise or errors. In addition, the wearable systems should provide privacy and security of the data being acquired and monitored. Further studies and more clinical evaluations are required to be carried out to evaluate the accuracy of the system for use in day-to-day use of subjects.

\section{ACKNOWLEDGEMENTS}

The authors would like to thank Dr. Karthik Udupa of Vatsalya Hospital Mysore, India for helping to collect the healthy subject's ECG \& PPG data. This study was supported by Maharaja Education Trust, Mysore, India.

\section{AUTHOR CONTRIBUTIONS}

P. S. Pandian contributed to the concept and design of the study. He also contributed towards design 
of dry electrodes for the physiological data acquisition and also helped in the critical revision of the work.

M. G. Srinivasa contributed towards the data collection, testing of the hardware, data analysis and writing of the paper.

\section{CONFLICTS OF INTEREST}

The authors declare no conflict of interest.

\section{REFERENCES}

1. Raskovic, D., Martin, T. and Jovanov, E. (2004) Medical Monitoring Applications for Wearable Computing. The Computer Journal, 47, 495-504. https://doi.org/10.1093/comjnl/47.4.495

2. Martin, T., Jovanov, E. and Raskovic, D. (2000) Issues in Wearable Computing for Medical Monitoring Applications: A Case Study of a Wearable ECG Monitoring Device. Proceedings. of the 4th International Symposium on Wearable Computers, Atlanta, GA, 16-17 October 2000, 43-49. https://doi.org/10.1109/ISWC.2000.888463

3. Kim, Y., Lee, S.S. and Lee, S.K. (2015) Coexistence of Zig Bee-Based WBAN and WiFi for Health Telemonitoring Systems. IEEE Journal of Biomedical and Health Informatics, 20, 222-230.

https://doi.org/10.1109/JBHI.2014.2387867

4. Egbogah, E.E. and Fapojuwo, A.O. (2013) Achieving Energ Efficient Transmission in Wireless Body Area Networks for the Physiological Monitoring of Military Soldiers. 2013 IEEE Military Communications Conference (MILCOM 2013), San Diego, CA, 18-20 November 2013. https://doi.org/10.1109/MILCOM.2013.233

5. Moulik, S., Misra, S. and Chakraborty, C. (2015) CAPCoS: Context-Aware PAN Coordinator Selection for Health Monitoring of Soldiers in Battlefield. 2015 IEEE International Conference on Advanced Networks and Telecommunications Systems (ANTS), Kolkata, India, 15-18 December 2015.

https://doi.org/10.1109/ANTS.2015.7413650

6. Mundt, C.W., Montgomery, K.N., Udoh, U.E., Barker, V.N., Thonier, G.C., Tellier, A.M., et al. (2005) A Multi Parameter Wearable Physiologic Monitoring System for Space and Terrestrial Applications. IEEE Transactions on Information Technology in Biomedicine, 9, 382-391. https://doi.org/10.1109/TITB.2005.854509

7. Aqueveque, P., Gutierrez, C., Saavedra, F., Pino, E.J., Morales, A.S. and Wiechmann, E. (2017) Monitoring Physiological Variables of Mining Workers at High Altitude. IEEE Transactions on Industry Applications, 53.

8. Hazarika, P. (2016) Implementation of Smart Safety Helmet for Coal Mine Workers. 2016 IEEE $1^{\text {st }}$ International Conference on Power Electronics, Intelligent Control and Energy Systems (ICPEICES), Delhi, India, 4-6 July 2016. https://doi.org/10.1109/ICPEICES.2016.7853311

9. Maity, T., Das, P.S. and Mukherjee, M. (2012) A Wireless Surveillance and Safety System for Mine Workers Based on Zigbee. $20121^{\text {st }}$ International Conference on Recent Advances in Information Technology (RAIT), Dhanbad, India, 15-17 March 2012. https://doi.org/10.1109/RAIT.2012.6194496

10. Potirakis, S., Mitilineos, S., Chatzistamatis, P., Vassiliadis, S., Primentas, A., Kogias, D., Michailidis, E.T., Rangoussi, M., Bahadır, S.K., Atalay, O., Kalaoglu, F. and Saglam, Y. (2016) Physiological Parameters Monitoring of Fire-Fighters by Means of a Wearable Wireless Sensor System. 2016 IOP Science Conference Series. Material Science Engineering 108012011, March 2016.

11. Coca, A., Roberge, R.J., Williams, W.J., Landsittel, D.P., Powell, J.B. and Palmiero, A. (2009) Physiological Monitoring in Firefighter Ensembles: Wearable Plethysmographic Sensor Vest versus Standard Equipment. Journal of Occupational and Environmental Hygiene, 7, 109-114. https://doi.org/10.1080/15459620903455722

12. Bu, Y., Wu, W., Zeng, X.Y., Koehl, L. and Tartare, G. (2015) A Wearable Intelligent System for Real Time Monitoring Fire Fighter's Physiological State and Predicting Dangers. 2015 IEEE $16^{\text {th }}$ International Conference on Communication Technology (ICCT), China, 8-20 October 2015. 
13. Hiware, A. and Tet, A.D. Sudden Infant Death Monitoring Using Smart Wearable System. International Journal of Science, Engineering and Technology Research (IJSETR), 6.

14. Fernandes, D., Ferreira, A.G., Branco, S., Abrishambaf, R., Carvalho, H., Mendes, J., Cabral, J. and Rocha, A. (2016) Energy Saving Mechanism for a Smart Wearable System: Monitoring Infants during the Sleep. 2016 IEEE International Conference on Industrial Technology (ICIT), Taipei, 14-17 March 2016. https://doi.org/10.1109/ICIT.2016.7475062

15. Oliver, N. and Flores-Mangas, F. (2007) HealthGear: Automatic Sleep Apnea Detection and Monitoring with a Mobile Phone. Journal of Communications, 2, 1-9.

16. Sannino, G., De Falco, I. and De Pietro, G. (2014) Monitoring Obstructive Sleep Apnea by Means of a Real Time Mobile System Based on the Automatic Extraction of Sets of Rules through Differential Evolution. Journal of Biomedical Informatics, 49, 84-100. https://doi.org/10.1016/j.jbi.2014.02.015

17. Paradiso, R., Loriga, G. and Taccini, N. (2005) A Wearable Health Care System Based on Knitted Integrated Sensors. IEEE Transactions on Information Technology in Biomedicine, 9, 337-344. https://doi.org/10.1109/TITB.2005.854512

18. Pandian, P.S., Mohanavelu, K., Safeer, K.P., Kotresh, T.M., Shakunthala, D.T., Gopal, P. and Padaki, V.C. (2008) Smart Vest: Wearable Multi-Parameter Remote Physiological Monitoring System. Medical Engineering \& Physics, 466-477. https://doi.org/10.1016/j.medengphy.2007.05.014

19. Zheng, Y., Leung, B., Sy, S., Zhang, Y. and Poon, C.C. (2012) A Clip-Free Eyeglasses-Based Wearable Monitoring Device for Measuring Photoplethysmograhic Signals. Conference Proceedings in IEEE Engineering Medicine and Biology Society, San Diego, 28 August-1 September 2012, 5022-5025.

20. Anliker, U., Ward, J.A., Lukowicz, P., Tröster, G., Dolveck, F., Baer, M., Keita, F., Schenker, E.B., Catarsi, F., Coluccini, L., Belardinelli, A., Shklarski, D., Alon, M., Hirt, E., Schmid, R. and Vuskovic, M. (2004) AMON: A Wearable Multiparameter Medical Monitoring and Alert System. IEEE Transactions on Information in Biomedicine, 8, 415-427. https://doi.org/10.1109/TITB.2004.837888

21. Malhi, K., Chandra, S., Schnepper, J., Haefke, M. and Ewald, H. (2012) A Zigbee Based Wearable Physiological Parameters Monitoring System. IEEE Sensors Journal, 12, 423-430. https://doi.org/10.1109/JSEN.2010.2091719

22. Mundt, C.W., Montgomery, K.N., Udoh, U.E., Barker, V.N., Thonier, G.C., Tellier, A.M., Ricks, R.D., Darling, R.B., Cagle, Y.D., Cabrol, N.A., Ruoss, S.J., Swain, J.L., Hines, J.W. and Kovacs, G.T.A. (2005) A Multiparameter Wearable Physiologic Monitoring System for Space and Terrestrial Applications. IEEE Transactions on Information Technology in Biomedicine, 9, 382-391. https://doi.org/10.1109/TITB.2005.854509

23. Halin, N., Junnila, M., Loula, P. and Aarnio, P. (2005) The LifeShirt System for Wireless Patient Monitoring in the Operating Room. Journal of Telemedicine and Telecare, 11, 41-43.

https://doi.org/10.1258/135763305775124623

24. Coyle, S., Lau, K.-T., Moyna, N., O’Gorman, D., Diamond, D., Di Francesco, F., Costanzo, D., Salvo, P., Trivella, M.G., De Rossi, D.E., Taccini, N., Paradiso, R., Porchet, J.-A., Ridolfi, A., Luprano, J., Chuzel, C., Lanier, T., Revol-Cavalier, F., Schoumacker, S., Mourier, V., Chartier, I., Convert, R., De-Moncuit, H. and Bini, C. (2010) BIOTEX-Biosensing Textiles for Personalised Healthcare Management. IEEE Transactions on Information Technology in Biomedicine, 14, 364-370. https://doi.org/10.1109/TITB.2009.2038484

25. Jovanov, E., Milenkovic, A., Otto, C. and de Groen, P.C. (2005) A Wireless Body Area Network of Intelligent Motion Sensors for Computer Assisted Physical Rehabilitation. Journal of Neuro Engineering and Rehabilitation, 2, 6.

26. Al Rasyid, M.U.H., Lee, B.-H. and Sudarsono, A. (2015) Wireless Body Area Network for Monitoring Body Temperature, Heart Beat and Oxygen in Blood. International Seminar on Intelligent Technology and Its Applications, Surabaya, 20-21 May 2015, 95-98. 
27. Abidoye, A.P., Azeez, N.A., Adesina, A.O., Agbele, K.K. and Nyongesa, H.O. (2011) Using Wearable Sensors for Remote Healthcare Monitoring System. Journal of Sensor Technology, 1, 22-28. https://doi.org/10.4236/jst.2011.12004

28. Thwe, H.M. and Tun, H.M. (2015) Patient Health Monitoring Using Wireless Body Area Network. International Journal of Scientific \& Technology Research, 4, 364-368.

29. Kachuee, M., Kiani, M.M., Mohammadzade, H. and Shabany, M. (2017) Cuffless Blood Pressure Estimation Algorithms for Continuous Health-Care Monitoring. IEEE Transactions on Biomedical Engineering, 64, 859-869. https://doi.org/10.1109/TBME.2016.2580904

30. Tang, Z., Tamura, T., Sekine, M., Huang, M., Chen, W., Yoshida, M., Sakatani, K., Kobayashi, H. and Kanaya, S. (2017) A Chair for Cuffless Real-Time Estimation of Systolic Blood Pressure Based on Pulse Arrival Time. IEEE Journal of Biomedical and Health Informatics, 21, 1194-1205. https://doi.org/10.1109/JBHI.2016.2614962

31. Mbachu, C.B. and Offor, K.J. (2013) Reduction of Power Line Noise in ECG Signal Using FIR Digital Filter Implemented with Hamming Window. International Journal of Science, Environment and Technology, 2, 1380-1387.

32. Arya, R. and Jaiswal, S. (2015) Design of Low Pass FIR Filters Using Kaiser Window Function with Variable $\operatorname{Beta}(\beta)$. International Journal of Multi-Disciplinary and Current Research, 3, 220-224.

33. Bland, J.M. and Altman, D.G. (2010) Statistical Methods for Assessing Agreement between Two Methods of Clinical Measurement. International Journal of Nursing studies, 47, 931-936.

https://doi.org/10.1016/j.ijnurstu.2009.10.001

34. Griffiths, P. and Murrells, T. (2010) Reliability Assessment and Approaches to Determining Agreement between Measurements: Classic Paper. International Journal of Nursing Studies, 47, 937-938.

https://doi.org/10.1016/j.ijnurstu.2010.03.004

35. Oweis, R.J., Basim, O. and Al-Tabbaa, B.O. (2014) QRS Detection and Heart Rate Variability Analysis: A Survey. Biomedical Science and Engineering, 2, 13-34.

36. Milagro, F.J. (2016) Poincare Plot Analysis and Graphical User Interface Development for the Study of Heart Rate Variability in Asthmatic Children. Master of Science Thesis, Tampere University of Technology.

37. Shaffer, F. and Ginsberg, J.P. (2017) An Overview of Heart Rate Variability Metrics and Norms. Frontiers in Public Health, 5, 1-17. https://doi.org/10.3389/fpubh.2017.00258

38. Tjolleng, A., Jung, K., Hong, W., Lee, W., Lee, B., You, H., Son, J. and Park, S. (2017) Classification of a Driver's Cognitive Workload Levels Using Artificial Neural Network on ECG Signals. Applied Ergonomics, 59, 326-332. https://doi.org/10.1016/j.apergo.2016.09.013

39. Task Force of The European Society of Cardiology (1996) Guidelines Heart Rate Variability. European Heart Journal, 17, 354-381.

40. Task Force of the European Society of Cardiology the North American Society of Pacing Electrophysiology (1997) Heart Rate Variability: Standards of Measurement, Physiological Interpretation, and Clinical Use. Circulation, 93, 1043-1065.

41. Billman, G., Huikuri, H., Sacha, J. and Trimmel, K. (2015) An Introduction to Heart Rate Variability: Methodological Considerations and Clinical Applications. Frontiers in Physiology, 6, 1-3.

https://doi.org/10.3389/fphys.2015.00055

42. Kleiger, R.E., Stein, P.K. and Bigger, J.T. (2005) Heart Rate Variability: Measurement and Clinical Utility. Annals of Noninvasiv Electrocardiology, 10, 88-101. https://doi.org/10.1111/j.1542-474X.2005.10101.x

43. Singh, D., Vinod, K. and Saxena, S. (2004) Sampling Frequency of the RR Interval Time Series for Spectral Analysis of Heart Rate Variability. Journal of Medical Engineering \& Technology, 28, 263-272. 


\section{https://doi.org/10.1080/03091900410001662350}

44. Patel, M., Lal, S.K., Kavanagh, D. and Rossiter, P. (2011) Applying Neural Network Analysis on Heart Rate Variability Data to Assess Driver Fatigue. Expert Systems with Applications, 38, 7235-7242. https://doi.org/10.1016/j.eswa.2010.12.028

45. Brennan, M., Palaniswami, M. and Kamen, P.W. (2001) Do Existing Measures of Poincare Plot Geometry Reflect Nonlinear Features of Heart Rate Variability? IEEE Transactions on Biomedical Engineering, 48, 1342-1347. https://doi.org/10.1109/10.959330

46. Niskanen, J.P., Tarvainen, M.P., Ranta-Aho, P.O. and Karjalainen, P.A. (2004) Software for Advanced HRV Analysis. Computer Methods and Programs in Biomedicine, 76, 73-81. https://doi.org/10.1016/j.cmpb.2004.03.004

47. Ribeiro, D., Fu, L., Carlos, L.D. and Cunha, J.P. (2011) A Novel Dry Active Biosignal Electrode Based on an Hybrid Organic-Inorganic Interface Material. IEEE Sensors Journal, 11, 2241-2245. https://doi.org/10.1109/JSEN.2011.2114649

48. Xie, L., Yang, G., Mäntysalo, M., Xu, L.L., Jonsson, F. and Zheng, L.R. (2012) Heterogeneous Integration of Bio-Sensing System On-Chip and Printed Electronics. IEEE Journal on Emerging and Selected Topics in Circuits and Systems, 2, 672-682.

49. Chandrakar, C. and Kowar, M.K. (2012) Denoising ECG Signals Using Adaptive Filter Algorithm. International Journal of Soft Computing and Engineering, 2, 120-123.

50. Luong, D.T., Thuan, N.D. and Hoang, D.H. (2015) Removal of Power Line Interference from Electrocardiograph (ECG) Using Proposed Adaptive Filter Algorithm. Global Journal of Computer Science and Technology, 15. 